\title{
COORDINATION MECHANISMS OF A THREE-LAYER SUPPLY CHAIN UNDER DEMAND AND SUPPLY RISK UNCERTAINTIES
}

\author{
Bibhas C. Giri*, Joyanta Kumar Majhi and Kripasindhu Chaudhuri
}

\begin{abstract}
This paper considers a newsvendor model for a single product to focus on the importance of coordination under demand and supply uncertainties where the raw materials are procured from two unreliable suppliers without any emergency resource; the main supplier (which is cheaper but more unreliable) is prone to random supply disruption and, therefore, it can satisfy all or nothing of the buyer's order, while the backup supplier (which is expensive but less unreliable) is prone to random yield and, therefore, can satisfy only a random fraction of the buyer's order. From the numerical results, we observe that it would be optimal to over-utilize the backup supplier and under-utilize the main supplier if the maximum growth in supply risk results from supply disruption. On the other hand, when the growth in supply risk occurs mainly due to increase in yield risk, the optimal risk mitigation strategy would be to increase the use of the backup supplier and decrease the use of the main supplier. We propose the price only contract and a new revenue sharing contract to mitigate demand and supply uncertainties in the decentralized model, and observe that the revenue sharing contract can fully coordinate the supply chain with win-win outcome for all entities involved in the supply chain.
\end{abstract}

Mathematics Subject Classification. 90B05, 90B06.

Received October 21, 2019. Accepted September 15, 2020.

\section{INTRODUCTION}

From the World Trade Center terrorist attack on 11 September, 2001 and blackout on 14 August, 2003 in the U.S. to recent political instability, natural disasters and destructive competitive acts increase the complexity, uncertainty and ambiguity of globalized supply chain. There are mainly two kinds of risk of uncertainty that affect supply chain management and network design. The first risk of uncertainty grows from the matter of demand and supply coordination and the second one grows from supply uncertainty which is emblematically modelled as complete supply disruption where supply halts completely, or yield uncertainty where the supplied quantity can fulfil a random fraction of the placed order size. We incorporate such supply uncertainties with normal demand-supply coordination risks. This paper builds on the literature regarding the management of the risk of uncertainty, and on the framework of supply chain coordination.

Keywords. Demand uncertainty, random yield, supply disruption, dual sourcing, three-echelon supply chain, channel coordination.

Department of Mathematics, Jadavpur University, Kolkata 700032, India.

*Corresponding author: bcgiri.jumath@gmail.com 
The supply-demand coordination risk is not new; it has been the central concern of activities in the literature of supply chain management since the last decade $[6,14-16,30]$. In recent years, the negative impact of demand fluctuation on the performance of supply chains has been studied under complex scenarios like asymmetric information and market instability, which becomes more complex when the supply chain has to deal with short life-cycle products such as vegetables, toys, stylish goods, etc. Also, growing modern technologies and intense global competition have reduced the life-cycle of other merchandises like computer chips, semiconductors and automobile spare parts $[9,17,23,34]$. Consequently, demand fluctuation for such products gets more attention of a buyer when it makes procurement plans.

In many industrial scenarios, the production process of a supplier is subject to random yield due to many reasons such as shortage of raw materials and labour, machine breakdown, natural interruption, etc. As a result, a supplier is only able to fulfill its buyer's order partially. In semiconductor industries, the actual yield often differs from the planned production. The exact yield quantity can never be anticipated for agricultural products due to weather, fertility of land, etc. [10]. To fulfill supply covenant, many companies set a higher production level than the order level decision, which might lead to the issue of over-production for the supplier. If the supplier does not want the risk of over-production, the buying firm may increase the order level to mitigate the risk of random yield of its upstream firm [20].

To excel in intense global competition, today's supply chain is becoming more globalised to enjoy cheaper raw material, lower labour cost, tax rebate, advance manufacturing technologies and other financial benefits, all of which reduce the production cost of a product. Such globalized supply chain networks frequently experience supply disruption arising from operational contingencies (like system failure, equipment shortage, web server error, strike), natural hazards (like hurricane, earthquake, storm), political instability and terrorism. Taiwan earthquake in 1999 halted the production of many semiconductor manufacturing companies causing shipping disruption of $70 \%$ of the world's graphics cards and $10 \%$ of data hard disk components [32]. Emission of fire from Eyjafjllajokull volcano in Iceland on 20th March, 2010 sent shock waves through several production plants in Europe due to many air transport cancellations throughout the world. A chemical accident in Bhopal in India drove serious environmental and massive economic consequences [26].

To hedge against uncertain supply disruption, many firms are realising the importance of several mitigation strategies. One of the simplest and effective policies adopted by several buyers is "multi-sourcing policy" which allows the buyer to have more than one resource providing similar quality attributes but may differ in terms of pricing. Another one is "contract agreement policy" among all the supply chain entities. Use of several resources or contracts is a critical but crucial decision for buyers, especially for them who produce short lifecycle products. Then how to envisage a contract mechanism under multi-sourcing strategies to reduce stock-out risk is an interesting challenge to the buying firms. In this paper, we investigate risk assessment and risk mitigation strategies to make the supply chain more elastic from the perspective of individual entities as well as the entire channel through implementation of contract mechanism among the chain members.

The existing literature $[2,18,19,24]$ has addressed the issue by studying a single period problem where a buyer sources a single short life-cycle product from an unreliable but cheaper supplier subject to disruption, and a perfectly reliable backup supplier who is always available to mitigate the buyer's unreliable supplier's disruption risk at a higher wholesale price. Now, the question arises: how is a backup supplier always be perfectly reliable when it has a production process and every production process is subject to random yield? Our main goal is to design a joint sourcing and contracting policy that enables supply chain entities to mitigate both demand and supply risks of uncertainty when procurement is made from two unreliable suppliers.

We consider a single period three-echelon supply chain with three possible uncertainties (independent of each other), in which a retailer faces an uncertain market demand for a short shelf-life product and sources it from a manufacturer under voluntary regimes. The manufacturer sources the raw materials from two unreliable suppliers without any emergency resource. The manufacturer's main supplier who delivers the order quantity at a cheaper wholesale price is prone to disruption and, therefore, may deliver all or nothing of the manufacturer's order, while the backup supplier who provides similar quality product at a comparatively higher wholesale price is prone to random yield and, therefore, can only fulfill a random fraction of the manufacturer's order. The two 
unreliable sources are usually geographically dispersed so that a supply risk at one supplier will not affect the other supplier i.e., risks of supply uncertainty at both the suppliers are independent. In this paper, we assume that both random yield and disruption risk are unresolved when the manufacturer places its order to both the unreliable suppliers simultaneously.

Under voluntary regime, one can look for a contract mechanism to cope with the demand-supply uncertainty. Available popular contract agreements such as wholesale price, buyback, quantity flexibility, revenue sharing, sales rebate, and quantity discount are limited within only two levels. These contracts are extendable in a multilevel supply chain by installing them between any two adjacent pairs of supply chain entities. But a pair-wise contract in a multi-level supply chain has a drawback from the perspective of simultaneous implementation i.e., there may occur a situation where a firm can be benefitted even without signing the agreement when other entities have already signed [36]. Van Der Rhee [36] proposed a spanning revenue sharing contract in which one supply chain member takes the lead in making a single contract with all other entities in the supply chain. In our model, we assume that the retailer takes the lead in negotiating a revenue sharing contract with all other supply chain members to prevent the two-sided supply-demand uncertainty. Through this agreement, the retailer would take the optimal decisions on the following aspects. Under which conditions, the spanning revenue sharing contract is desirable and how much to order from the manufacturer then? On the other hand, the manufacturer also needs to decide its optimal order quantities from both the suppliers. In this contract, the manufacturer and both the suppliers are incentivised by the retailer to decrease their wholesale prices so that the retailer can increase its order quantity to satisfy customer demand such that the expected profit of the entire supply chain increases. Moreover, both the suppliers and the manufacturer are fully aware of their roles to enhance system's performance and must desire to get some compensation for their reduced wholesale prices, which is given at the end of the selling season by the retailer in terms of share of its revenue.

The rest of the paper is organized as follows: Section 2 indicates the position of the paper in the existing relevant literature. Section 3 introduces basic settings of the problem under consideration. Section 4 presents two benchmark models and their equilibrium solutions. In Section 5, the spanning revenue sharing contract is developed. A win-win situation that ensures chain coordination is also proposed in this section. Numerical results are analyzed in Section 6 for best practices in guiding supply disruption and demand uncertainty. We conclude the paper in Section 7, stating conditions for implementation of the proposed model and scopes of future research.

\section{LiteratuRE REVIEW}

A large number of studies on supply chain have considered that supply quantity equals the order quantity. However, in real business activities, the supply uncertainty is inevitable due to influence of many factors. For example, a supplier may fulfill a random fraction of an order (usually referred to as random yield) or the main supplier who is supposed to deliver the full order through in-house production, may suffer from disruption under which nothing will be delivered to the buyer. A lot of studies have emphasised on the issue of dual sourcing under supply risk. In fact, dual sourcing improves channel performance even when there is no supply uncertainty [5]. Mainly four important factors viz. supply uncertainty (due to random yield and supply disruption), sourcing strategy, availability of resources and buyer-supplier contracting relationship often determine each decisionmaking in business. Among the early researchers in disruption management, Meyer et al. [29] considered a single production process which is subject to random disruption. A large body of literature concentrates on discovering the optimal number of suppliers to enhance the channel ability in disruption management. Berger et al. $[3,4]$ investigated the issue of supplier selection where a buyer has to choose the optimal number of suppliers who are identical in terms of supply disruption. Ruiz-Torres and Mahmoodi [31] represented a decision tree which helps to find the optimal number of suppliers, and concluded that the optimal number of utilized suppliers is typically small as long as the suppliers are very unreliable and the cost of failure is very high. Evanov et al. [25] classified existing research works and application fields of different disruption risks and mitigation process. 
Chakraborty et al. [8] considered a single-retailer and two-suppliers supply chain with price-dependent random demand in which suppliers are subject to disruption.

Anupindi and Akella [1] addressed the issue of quantity allocation of a buyer between two unreliable suppliers. They studied three models under different delivery conditions, and determined the optimal allocation policies. Dada et al. [13] considered order allocation in a newsvendor model in which multiple suppliers with different degrees of reliability and prices were utilized. They concluded that, for order allocation among the suppliers, the price is a more effective measure than reliability of a supplier. Tomlin [35] studied optimal mitigation strategies for a short life-cycle product where the supply base for the buyer is subject to random disruption. He showed that disruption mitigation is not possible only through inventory control; supplier's diversification is an effective mitigation strategy in that case too. In contrast to Tomlin's [35] model, Chopra et al. [12] considered two suppliers - one is unreliable due to both random yield and disruption uncertainty, and the other one is perfectly reliable. Their mitigation strategy was to reserve a quantity at the reliable supplier and exercise up to that reserved amount if the first supplier can't fulfill the demand due to random yield or supply disruption. Our modelling structure is different from those of the above papers which consider a fully reliable backup supplier to mitigate supply uncertainty.

Chen and Yang [11] developed a supply chain model where the buyer purchased the remaining items from a backup supplier to satisfy the stochastic demand, and the production process of the primary supplier is subject to random yield. Asian and Nie [2] investigated a joint ordering and procurement problem with a main supplier who is prone to disruption, and a reliable backup supplier. The retailer signs an option contract with the backup supplier and also enjoys the option of buying from an emergency resource. The backup supplier's optimal procurement and the retailer's ordering decisions were characterized by them. Giri and Bardhan [19] discussed a supply chain model with a retailer and a manufacturer under both random yield in production and disruption risk. The retailer has the option for capacity reservation with a backup supplier. The authors considered a penalty contract and characterized the retailer's joint ordering and reserving decisions and the manufacturer's pricing decision. Xu et al. [37] studied a three-echelon supply chain to investigate how contract mechanism can reduce the risk of supply disruption. Zeng and Xia [38] discussed the way to manage the supply disruption by constructing a buyer-backup supplier partnership. They revealed clear action plans for the entities through a decision-tree approach when supply disruption occurs thereby significantly lowering its supply risk. These models differ from our proposed model in the sense that none of them brings all the suppliers under a single contract, and considers an unreliable backup supplier.

Our work is closely related to the work of $\mathrm{Li}[27]$ who developed a model in which the deterministic demand is met up by two unreliable suppliers: one supplier is subject to random yield and the other one is unreliable due to disruption. They investigated three models depending on procurement strategies without any reliable supplier but they didn't consider channel coordination. Our article is also related to the work of Dada et al. [13] in terms of supplier utilization. In the event of supplier selection for optimal order allocation, we consider a cheaper supplier having the risk of supply disruption and an expensive supplier having random yield in production, and find their relative uses. Our paper expands on the acumen of Dada et al. [13] by individually considering whether the risk of supply uncertainty occurs from random yield or supply disruption.

\section{PROBLEM DESCRIPTION}

We consider a supply chain where a single manufacturer sources raw materials from two unreliable suppliers (main supplier and backup supplier) to respond the order of a retailer who sells a short life-cycle product with uncertain demand over a single period of time. The main supplier who delivers order quantity at a cheaper wholesale price is subject to random disruption and may deliver all or nothing of the manufacturer's order, while the backup supplier who provides similar quality product at a comparatively higher wholesale price is subject to random yield i.e., the backup supplier can fulfill only a random fraction of the manufacturer's order. From now onwards, we will term "main supplier" as the "cheaper supplier", and "backup supplier" as the "expensive supplier". For mathematical tractability, we consider the following assumptions: 


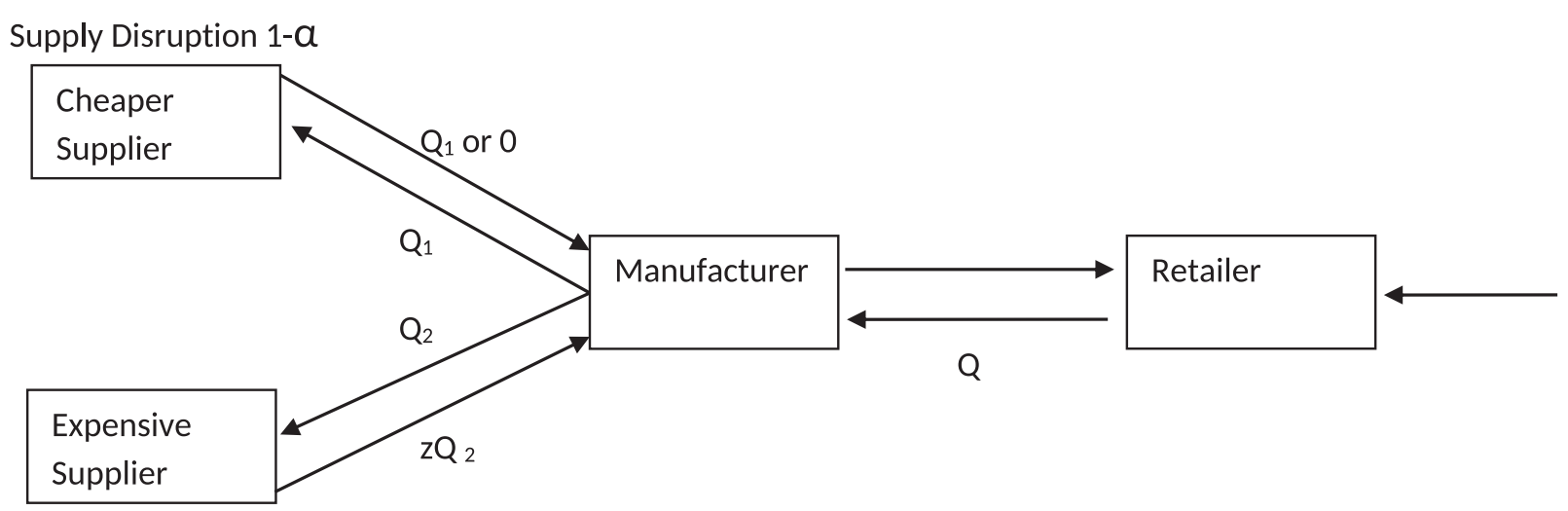

FIgURE 1. Three-layer supply chain model with two unreliable suppliers.

- Only one order can be placed by a supply chain entity during a single selling season.

- All four entities (manufacturer, retailer, and two unreliable suppliers) involved in the supply chain are risk-neutral and pursue their individual profit maximization.

- All the entities start with zero on-hand inventory i.e., there is no stock from previous period.

- There is a symmetric information flow under which all costs and profit parameters are known to each supply chain entity.

- All costs and profit parameters can be taken as exogenous parameters as all entities determine selling price/wholesale price and salvage value in advance and after that negotiate their order quantities.

The retailer faces a stochastic market demand $x$ which is a positive continuous random variable having a general distribution over interval $[l, u]$ with cumulative distribution function $F(\cdot)$ and probability density function $f(\cdot)$ with mean $\bar{x}$ and variance $\sigma_{x}^{2}$. The manufacturer submits order $Q_{1}$ to the cheaper supplier and $Q_{2}$ to the expensive supplier simultaneously before the realization of the supply state of the cheaper supplier and actual demand [27]. The cheaper supplier can deliver full order quantity $Q_{1}$ with a wholesale price $w_{s 1}$ if not disrupted, but it delivers nothing, if disrupted. The probability that the cheaper supplier is not disrupted is $\alpha \in[0,1]$. On the other hand, the expensive supplier can only deliver a random fraction $z$ (having $\operatorname{pdf} h(\cdot)$, cdf $H(\cdot)$ and range $[c, d], 0 \leq c<d \leq 1)$ of order quantity $Q_{2}$ with a relatively higher wholesale price $w_{s 2}$ than that of the cheaper supplier (i.e., $w_{s 2}>w_{s 1}$ ) (Fig. 1).

Two contract mechanisms are considered in this model viz. price-only contract and spanning revenue sharing contract. In price-only contract, the retailer and the manufacturer decide their order quantities based on their newsvendor problems without considering profit of the system. In this situation, the retailer takes the risks of demand and supply uncertainties. Meanwhile the cheaper supplier takes the responsibility of its undelivered raw materials, if its supply is disrupted. Under spanning revenue sharing mechanism, the supplier and the manufacturer decrease their wholesale prices to provide incentive to the manufacturer and the retailer, respectively. As a consequence, the retailer decides to increase its order quantity so that the availability of the final product to the end customer is increased. In this case, both the supplier and the manufacturer share the risks of demand and supply uncertainties with the retailer. In contrast, the retailer also shares the risk of random yield or disruption with the suppliers and the manufacturer by sharing its revenue with them as a compensation for their decreased wholesale prices. We assume that the retailer's selling price is $p$, unit goodwill loss for any unsatisfied demand is $b_{r}$ and salvage value of any leftover inventory is $h_{r}$. Notations used in developing the proposed model are listed below:

More symbols will be defined whenever needed. To avoid trivial cases, the following assumptions are made: $h_{s 1}<c_{s 1}<w_{s 1} ; h_{m}<w_{s 1} ; w_{s 2}+c_{m}<w_{m} ; h_{r}<w_{m}+c_{r}<p ; c_{s 2} / \bar{z}<w_{s 2}$. These inequalities prevent the supply chain from infinite production and assure that each chain member makes positive profit. 


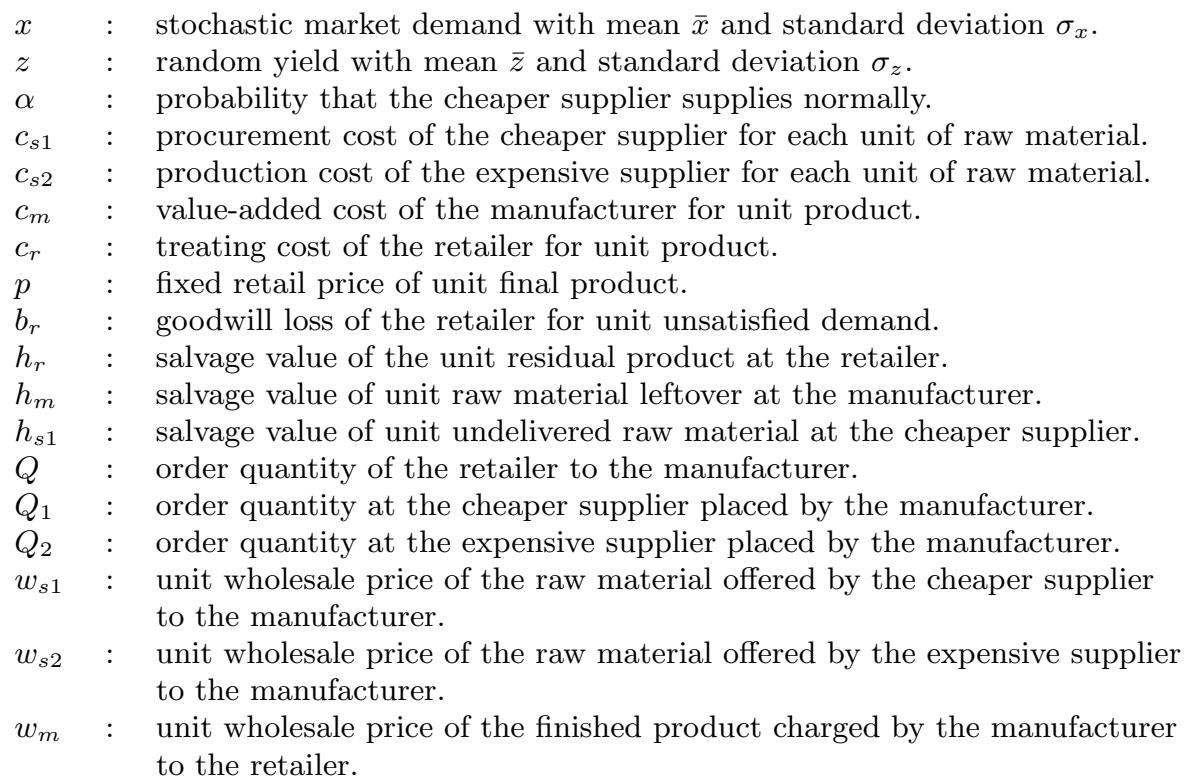

\section{BenCHMARK MODELS}

In this section, two benchmark models are considered viz. centralized model and decentralized model with price-only contract.

\subsection{Centralized model}

In reality, although all the supply chain members act independently and take decisions that optimize their respective objective functions, the centralized model is useful to establish a performance benchmark. Conceptually here is only one central decision maker who maximizes the system-wide profit. The expected profit of the entire supply chain is given by

$$
\begin{aligned}
\Pi_{c}\left(Q, Q_{1}, Q_{2}\right)= & \alpha\left(p+b_{r}-h_{r}\right) E\left[\min \left\{x, Q, Q_{1}+z Q_{2}\right\}\right]-\alpha\left(c_{m}+c_{r}+h_{m}-h_{r}\right) \\
& \times E\left[\min \left\{Q, Q_{1}+z Q_{2}\right\}\right]-\alpha\left(c_{s 1}-h_{m}\right) Q_{1}+(1-\alpha)\left(p+b_{r}-h_{r}\right) \\
& \times E\left[\min \left\{x, Q, z Q_{2}\right\}\right]-(1-\alpha)\left(c_{m}+c_{r}+h_{m}-h_{r}\right) \\
& \times E\left[\min \left\{Q, z Q_{2}\right\}\right]-(1-\alpha)\left(c_{s 1}-h_{s 1}\right) Q_{1} \\
& -\left(c_{s 2}-h_{m} \bar{z}\right) Q_{2}-b_{r} \bar{x}
\end{aligned}
$$

where the first three terms represent normal working state (with probability $\alpha$ ) of the cheaper supplier and the next three terms refer to the scenario where the cheaper supplier is disrupted with probability $(1-\alpha)$ and the final two terms are independent of probability of disruption. We obtain an equivalent representation of the entire system's profit function as follows:

$$
\begin{aligned}
\Pi_{c}\left(Q, Q_{1}, Q_{2}\right)= & \alpha\left(p+b_{r}-h_{r}\right) \times\left\{\int _ { c } ^ { \frac { Q - Q _ { 1 } } { Q _ { 2 } } } \left(\int_{l}^{Q_{1}+z Q_{2}} x f(x) \mathrm{d} x\right.\right. \\
& \left.+\int_{Q_{1}+z Q_{2}}^{u}\left(Q_{1}+z Q_{2}\right) f(x) \mathrm{d} x\right) h(z) \mathrm{d} z+\int_{\frac{Q-Q_{1}}{Q_{2}}}^{d}\left(\int_{l}^{Q} x f(x) \mathrm{d} x\right. \\
& \left.\left.+\int_{Q}^{u} Q f(x) \mathrm{d} x\right) h(z) \mathrm{d} z\right\}+(1-\alpha)\left(p+b_{r}-h_{r}\right)\left\{\int _ { c } ^ { \frac { Q } { Q _ { 2 } } } \left(\int_{l}^{z Q_{2}} x f(x) \mathrm{d} x\right.\right.
\end{aligned}
$$




$$
\begin{aligned}
& \left.\left.+\int_{z Q_{2}}^{u} z Q_{2} f(x) \mathrm{d} x\right) h(z) \mathrm{d} z+\int_{\frac{Q}{Q_{2}}}^{d}\left(\int_{l}^{Q} x f(x) \mathrm{d} x+\int_{Q}^{u} Q f(x) \mathrm{d} x\right) h(z) \mathrm{d} z\right\} \\
& -\alpha\left(c_{m}+c_{r}+h_{m}-h_{r}\right) \times\left\{\int_{c}^{\frac{Q-Q_{1}}{Q_{2}}}\left(Q_{1}+z Q_{2}\right) h(z) \mathrm{d} z\right. \\
& \left.+\int_{\frac{Q-Q_{1}}{Q_{2}}}^{d} Q h(z) \mathrm{d} z\right\}-(1-\alpha)\left(c_{m}+c_{r}+h_{m}-h_{r}\right)\left\{\int_{c}^{\frac{Q}{Q_{2}}} z Q_{2} h(z) \mathrm{d} z\right. \\
& \left.+\int_{\frac{Q}{Q_{2}}}^{d} Q h(z) \mathrm{d} z\right\}-\alpha\left(c_{s 1}-h_{m}\right) Q_{1}-(1-\alpha)\left(c_{s 1}-h_{s 1}\right) Q_{1}-\left(c_{s 2}-h_{m} \bar{z}\right) Q_{2}-b_{r} \bar{x} .
\end{aligned}
$$

Due to complexity of the profit function $\Pi_{c}\left(Q, Q_{1}, Q_{2}\right)$ in (4.2), it is difficult to show directly that $\Pi_{c}\left(Q, Q_{1}, Q_{2}\right)$ is jointly concave in $Q, Q_{1}$ and $Q_{2}$. We derive the following results to characterize the optimal decisions of the centralized model.

Theorem 4.1. The expected profit function $\Pi_{c}\left(Q, Q_{1}, Q_{2}\right)$ is concave in $Q$ and the optimal order quantity $Q^{c}$ is given by

$$
Q^{c}=F^{-1}\left(\frac{p+b_{r}-c_{m}-c_{r}-h_{m}}{p+b_{r}-h_{r}}\right)
$$

Proofs of Theorem 4.1 and all subsequent theorems and propositions are given in appendices.

Putting (4.3) in (4.2), we get

$$
\begin{aligned}
\Pi_{c}\left(Q_{1}, Q_{2}\right)= & \alpha\left(p+b_{r}-h_{r}\right)\left\{\int _ { c } ^ { \frac { Q ^ { c } - Q _ { 1 } } { Q _ { 2 } } } \left(\int_{l}^{Q_{1}+z Q_{2}} x f(x) \mathrm{d} x\right.\right. \\
& \left.+\int_{Q_{1}+z Q_{2}}^{u}\left(Q_{1}+z Q_{2}\right) f(x) \mathrm{d} x\right) h(z) \mathrm{d} z+\int_{\frac{Q^{c}-Q_{1}}{Q_{2}}}^{d}\left(\int_{l}^{Q^{c}} x f(x) \mathrm{d} x\right. \\
& \left.\left.+\int_{Q^{c}}^{u} Q^{c} f(x) \mathrm{d} x\right) h(z) \mathrm{d} z\right\}+(1-\alpha)\left(p+b_{r}-h_{r}\right)\left\{\int _ { c } ^ { \frac { Q ^ { c } } { Q _ { 2 } } } \left(\int_{l}^{z Q_{2}} x f(x) \mathrm{d} x\right.\right. \\
& \left.\left.+\int_{z Q_{2}}^{u} z Q_{2} f(x) \mathrm{d} x\right) h(z) \mathrm{d} z+\int_{\frac{Q^{c}}{Q_{2}}}^{d}\left(\int_{l}^{Q^{c}} x f(x) \mathrm{d} x+\int_{Q^{c}}^{u} Q^{c} f(x) \mathrm{d} x\right) h(z) \mathrm{d} z\right\} \\
& -\alpha\left(c_{m}+c_{r}+h_{m}-h_{r}\right) \times\left\{\int_{c}^{\frac{Q-Q_{1}}{Q_{2}}}\left(Q_{1}+z Q_{2}\right) h(z) \mathrm{d} z+\int_{\frac{Q-Q_{1}}{Q_{2}}}^{d} Q h(z) \mathrm{d} z\right\} \\
& -(1-\alpha)\left(c_{m}+c_{r}+h_{m}-h_{r}\right)\left\{\int_{c}^{\frac{Q^{c}}{Q_{2}}} z Q_{2} h(z) \mathrm{d} z+\int_{\frac{Q^{c}}{Q_{2}}}^{d} Q^{c} h(z) \mathrm{d} z\right\}-\alpha\left(c_{s 1}-h_{m}\right) Q_{1} \\
& -(1-\alpha)\left(c_{s 1}-h_{s 1}\right) Q_{1}-\left(c_{s 2}-h_{m} \bar{z}\right) Q_{2}-b_{r} \bar{x} .
\end{aligned}
$$

Proposition 4.2. The optimal order quantities $Q_{1}^{c}$ and $Q_{2}^{c}$ satisfy the following equations: 


$$
\begin{aligned}
\int_{c}^{\frac{Q^{c}-Q_{1}^{c}}{Q_{2}^{c}}} \bar{F}\left(Q_{1}^{c}+z Q_{2}^{c}\right) h(z) \mathrm{d} z= & \frac{\alpha\left(c_{s 1}-h_{m}\right)-(1-\alpha)\left(h_{s 1}-c_{s 1}\right)}{\alpha\left(p+b_{r}-h_{r}\right)} \\
& +\frac{\left(c_{m}+c_{r}+h_{m}-h_{r}\right)}{\left(p+b_{r}-h_{r}\right)} H\left(\frac{Q^{c}-Q_{1}^{c}}{Q_{2}^{c}}\right)
\end{aligned}
$$

and

$$
\begin{aligned}
\alpha \int_{c}^{\frac{Q^{c}-Q_{1}^{c}}{Q_{2}^{c}}} z \bar{F}\left(Q_{1}^{c}+z Q_{2}^{c}\right) h(z) \mathrm{d} z+(1-\alpha) \int_{c}^{\frac{Q^{c}}{Q_{2}^{c}}} z \bar{F} z Q_{2}^{c} h(z) \mathrm{d} z \\
=\frac{\left(c_{m}+c_{r}+h_{m}-h_{r}\right)}{\left(p+b_{r}-h_{r}\right)}\left[\alpha \int_{c}^{\frac{Q^{c}-Q_{1}^{c}}{Q_{2}^{c}}} z h(z) \mathrm{d} z+(1-\alpha) \int_{c}^{\frac{Q^{c}}{Q_{2}^{c}}} z h(z) \mathrm{d} z\right] \\
\quad+\frac{c_{s 2}-h_{m} \bar{z}}{\left(p+b_{r}-h_{r}\right)}
\end{aligned}
$$

where $F^{-1}(v)=\inf \{u: F(u)=v\}$ and $\bar{F}(v)=1-F(v)$, the survival function. In our model, the entire channel profit depends only on the order quantities. Therefore, by ordering $Q^{c}, Q_{1}^{c}$ and $Q_{2}^{c}$, the expected total profit is maximized and the maximum value is $\Pi_{c}\left(Q^{c}, Q_{1}^{c}, Q_{2}^{c}\right)$. From equation (4.3), we find that the optimal order quantity $Q^{c}$ is only affected by the exogenous parameters related to the final product, not by parameters (except $h_{m}$ ) related to the raw material, which is quite natural.

\subsection{Decentralized model with price-only contract}

In reality, all supply chain members are independent decision makers and they choose best decisions to maximize their individual profits. We now consider a decentralized system where there is price-only contract among the supply chain entities. The process flow in this decentralized setting is as follows:

First, both the raw-material suppliers determine their respective wholesale prices $w_{s 1}$ and $w_{s 2}$. Consequently the manufacturer determines its wholesale price $w_{m}$. Then, with the knowledge of disruption probability, demand and yield distributions, the retailer decides to order $Q$ units from the manufacturer. The manufacturer orders $Q_{1}$ units of raw material from the cheaper supplier with a disruption risk $(1-\alpha)$ and $Q_{2}$ units from the expensive supplier with a production yield risk $z$. Subsequently, the amount $\min \left\{Q, Q_{1}+z Q_{2}\right\}$ or $\min \left\{Q, z Q_{2}\right\}$ is shipped by the manufacturer according to the cheaper supplier's supply state up or down, respectively. Finally, the market demand $x$ occurs and the retailer sells the amount $\min \left\{x, Q, Q_{1}+z Q_{2}\right\}$ or $\min \left\{x, Q, z Q_{2}\right\}$ to the end-customer depending on whether there is no disruption or disruption, respectively, at the cheaper supplier.

We consider a Nash sequence where both the suppliers act as the first decision maker and the system is solved through backward induction. Therefore, the retailer first determines its optimal decisions. For given $Q_{1}, Q_{2}$, the retailer's profit function $\Pi_{r d}(Q)$ can be derived as follows:

$$
\begin{aligned}
\Pi_{r d}(Q)= & \alpha\left(p+b_{r}-h_{r}\right) E\left[\min \left\{x, Q, Q_{1}+z Q_{2}\right\}\right]-\alpha\left(w_{m}+c_{r}-h_{r}\right) \\
& \times E\left[\min \left\{Q, Q_{1}+z Q_{2}\right\}\right]+(1-\alpha)\left(p+b_{r}-h_{r}\right) E\left[\min \left\{x, Q, z Q_{2}\right\}\right] \\
& -(1-\alpha)\left(w_{m}+c_{r}-h_{r}\right) E\left[\min \left\{Q, z Q_{2}\right\}\right]-b_{r} \bar{x} .
\end{aligned}
$$

We can rewrite the above profit function as follows:

$$
\begin{aligned}
\Pi_{r d}(Q)= & \alpha\left(p+b_{r}-h_{r}\right)\left\{\int_{c}^{\frac{Q-Q_{1}}{Q_{2}}}\left(\int_{l}^{Q_{1}+z Q_{2}} x f(x) \mathrm{d} x+\int_{Q_{1}+z Q_{2}}^{u}\left(Q_{1}+z Q_{2}\right) f(x) \mathrm{d} x\right) h(z) \mathrm{d} z\right. \\
& \left.+\int_{\frac{Q-Q_{1}}{Q_{2}}}^{d}\left(\int_{l}^{Q} x f(x) \mathrm{d} x+\int_{Q}^{u} Q f(x) \mathrm{d} x\right) h(z) \mathrm{d} z\right\}+(1-\alpha)\left(p+b_{r}-h_{r}\right)
\end{aligned}
$$




$$
\begin{aligned}
& \left\{\int_{c}^{\frac{Q}{Q_{2}}}\left(\int_{l}^{z Q_{2}} x \times f(x) \mathrm{d} x+\int_{z Q_{2}}^{u} z Q_{2} f(x) \mathrm{d} x\right) h(z) \mathrm{d} z+\int_{\frac{Q}{Q_{2}}}^{d}\left(\int_{l}^{Q} x f(x) \mathrm{d} x+\int_{Q}^{u} Q f(x) \mathrm{d} x\right) h(z) \mathrm{d} z\right\} \\
& -\alpha\left(w_{m}+c_{r}-h_{r}\right)\left\{\int_{c}^{\frac{Q-Q_{1}}{Q_{2}}}\left(Q 1+z Q_{2}\right) h(z) \mathrm{d} z+\int_{\frac{Q-Q_{1}}{Q_{2}}}^{d} Q h(z) \mathrm{d} z\right\}-(1-\alpha) \\
& \times\left(w_{m}+c_{r}-h_{r}\right)\left\{\int_{c}^{\frac{Q}{Q_{2}}} z Q_{2} h(z) \mathrm{d} z+\int_{\frac{Q}{Q_{2}}}^{d} Q h(z) \mathrm{d} z\right\}-b_{r} \bar{x} .
\end{aligned}
$$

The optimal decision of the retailer is given in the following theorem.

Theorem 4.3. The profit function $\Pi_{r d}(Q)$ is concave in $Q$ and the optimal order quantity $Q^{d}$ is given by

$$
Q^{d}=F^{-1}\left(\frac{p+b_{r}-w_{m}-c_{r}}{p+b_{r}-h_{r}}\right)
$$

It is easy to see that $Q^{d}$ increases as the wholesale price $\left(w_{m}\right)$ of the manufacturer and the value-added cost $\left(c_{r}\right)$ of the retailer decrease, which meets our intuition.

Comparing $Q^{d}$ in (4.9) with the order quantity of the centralized system given in (4.3), we find that the retailer orders less in the decentralized benchmark model. This indicates that the decentralized system does not run as efficiently as the centralized system. After analyzing the retailer's problem and obtaining the optimal order quantity $Q^{d}$, we derive the manufacturer's expected profit function $\Pi_{m d}\left(Q_{1}, Q_{2}\right)$ as follows:

$$
\begin{aligned}
\Pi_{m d}\left(Q_{1}, Q_{2}\right)= & \alpha\left(w_{m}-c_{m}-h_{m}\right) E\left[\min \left\{Q, Q_{1}+z Q_{2}\right\}\right]-\alpha\left(w_{s 1}-h_{m}\right) Q_{1} \\
& +(1-\alpha)\left(w_{m}-c_{m}-h_{m}\right) E\left[\min \left\{Q, z Q_{2}\right\}\right]-\left(w_{s 2}-h_{m}\right) \bar{z} Q_{2}
\end{aligned}
$$

which can be written as

$$
\begin{aligned}
\Pi_{m d}\left(Q_{1}, Q_{2}\right)= & \alpha\left(w_{m}-c_{m}-h_{m}\right)\left\{\int_{c}^{\frac{Q-Q_{1}}{Q_{2}}}\left(Q_{1}+z Q_{2}\right) h(z) \mathrm{d} z+\int_{\frac{Q-Q_{1}}{Q_{2}}}^{d} Q h(z) \mathrm{d} z\right\} \\
& +(1-\alpha)\left(w_{m}-c_{m}-h_{m}\right)\left\{\int_{c}^{\frac{Q}{Q_{2}}} z Q_{2} h(z) \mathrm{d} z+\int_{\frac{Q}{Q_{2}}}^{d} Q h(z) \mathrm{d} z\right\} \\
& -\alpha\left(w_{s 1}-h_{m}\right) Q_{1}-\left(w_{s 2}-h_{m} \bar{z}\right) Q_{2} .
\end{aligned}
$$

We characterize the optimal decisions of the manufacturer in the following theorem.

Theorem 4.4. The manufacturer's profit function $\Pi_{m d}\left(Q_{1}, Q_{2}\right)$ is jointly concave in $Q_{1}$ and $Q_{2}$, and the optimal order quantities $Q_{1}^{d}$ and $Q_{2}^{d}$ satisfy the following equations:

$$
\begin{gathered}
Q_{1}^{d}=Q-Q_{2}^{d} H^{-1}\left(\frac{w_{s 1}-h_{m}}{w_{m}-c_{m}-h_{m}}\right) \\
\alpha \int_{c}^{\frac{Q-Q_{1}^{d}}{Q_{2}^{d}}} z h(z) \mathrm{d} z+(1-\alpha) \int_{c}^{\frac{Q}{Q_{2}^{d}}} z h(z) \mathrm{d} z=\frac{\left(w_{s 2}-h_{m}\right) \bar{z}}{\left(w_{m}-c_{m}-h_{m}\right)} .
\end{gathered}
$$

Based on Theorem 4.3, we notice that the cheaper supplier's expected profit function is increasing in $Q$ and decreasing in $Q_{2}$. Also, $Q_{1}^{d}$ is increasing in $w_{s 2}$ and decreasing in $w_{s 1}$, whereas $Q_{2}^{d}$ is increasing in $w_{s 1}$ and decreasing in $w_{s 2}$. The expected profit $\Pi_{s 2 d}$ of the expensive supplier is given by

$$
\Pi_{s 2 d}=\left(w_{s 2} \bar{z}-c_{s 2}\right) Q_{2}
$$


and the expected profit $\Pi_{s 1 d}$ of the cheaper supplier is given by

$$
\Pi_{s 1 d}=\alpha\left(w_{s 1}-c_{s 1}\right) Q_{1}+(1-\alpha)\left(h_{s 1}-c_{s 1}\right) Q_{1} .
$$

Under the price-only contract, the manufacturer has to face disruption risk and yield uncertainty of the suppliers. Hence it takes decisions without any promise to anyone. In this scenario, we assume that the wholesale prices are negotiated based on the firm's bargaining power, keeping a positive profit margin above a desired level of acceptance [2].

Now, we compare the above benchmark models in the following theorem:

Theorem 4.5. All the order quantities in the decentralized model are strictly less than their counterparts in the centralized model. Moreover, a lower order quantity leads to a lower expected profit of the supply chain.

Theorem 4.5 indicates that the maximum system efficiency is not achievable in the decentralized model with price-only contract even if all chain members maximize their own profits. In the decentralized scenario where the decision power is distributed over the chain members, there is a possible deviation from the optimal decisions obtained in the centralized model. To align each member's decision with the entire channel, contract mechanisms come into play. A contract or agreement prevents sub-optimization by removing the rivalry among the members without affecting the supply chain structure and its members' decision powers.

\section{Spanning ReVEnue Sharing CONTRACT}

In this section, we focus on the decentralized scenario with spanning revenue sharing (SRS) contract where the retailer guides the negotiation of revenue share among the chain members. This arrangement incentivizes each supplier to decrease its wholesale price, which influences the manufacturer to reduce its price too at the beginning of the selling season. The compensation for reduced wholesale price is given in terms of revenue share of the retailer with other entities, as a lower wholesale price gives an opportunity to the retailer to earn more revenue by satisfying more customers. We also examine whether the supply chain is coordinated under SRS contract i.e., the decentralized supply chain model with SRS contract achieves the same profit as that of the centralized benchmark model. Moreover, we characterize the chain members' participation problem for a win-win outcome. The time-line of events has the following sequence.

First, the retailer forecasts the customer demand, negotiates SRS contract with all upstream entities, decides its order quantity $Q$, and places its order to the manufacturer before the selling season. Based on the retailer's order quantity, the manufacturer orders $Q_{1}$ and $Q_{2}$ units of raw-materials to cheaper and expensive suppliers, respectively. After realization of the supply uncertainty, the manufacturer receives 0 or $Q_{1}$ units from the cheaper supplier depending on whether or not the cheaper supplier is disrupted, and securely receives $z Q_{2}$ (a random fraction of its order $Q_{2}$ ) units from the expensive supplier. After receiving raw materials from the suppliers, the manufacturer starts production and delivers to the retailer at once. At the retailer, if the demand is less than the on-hand inventory, the excess amount is salvaged; otherwise, the shortage cost incurs. At the end of the selling season, the retailer shares its revenue to all the upstream entities according to the rule of pricing under SRS contract. The SRS mechanism is administrated by three wholesale prices $w_{s 1}, w_{s 2}$ and $w_{m}$ and three revenue sharing ratios $\phi_{s 1}, \phi_{s 2}$ and $\phi_{m}\left(0 \leq \phi_{s 1}+\phi_{s 2}+\phi_{m}=\phi \leq 1\right)$ of the retailer's revenues that are shared with the cheaper supplier, expensive supplier and the manufacturer, respectively.

We first concentrate on the retailer's decision problem to determine the optimal order quantity $Q^{*}$ subject to any decision $\left(Q_{1}, Q_{2}\right)$ of the manufacturer. Then, we focus on the manufacturer's decision problem to obtain the optimal order quantities $Q_{1}^{*}$ and $Q_{2}^{*}$ to anticipate the retailer's optimal repercussion. The retailer's profit function $\Pi_{r c}(Q)$ under the spanning revenue sharing contract is derived as

$$
\begin{aligned}
\Pi_{r c}(Q)= & \alpha\left((1-\phi)\left(p-h_{r}\right)+b_{r}\right) E\left[\min \left\{x, Q, Q_{1}+z Q_{2}\right\}\right]-\alpha\left(w_{m}+c_{r}\right. \\
& \left.-(1-\phi) h_{r}\right) E\left[\min \left\{Q, Q_{1}+z Q_{2}\right\}\right]+(1-\alpha)\left((1-\phi)\left(p-h_{r}\right)+b_{r}\right)
\end{aligned}
$$




$$
\begin{aligned}
& \times E\left[\min \left\{x, Q, z Q_{2}\right\}\right]-(1-\alpha)\left(w_{m}+c_{r}-(1-\phi) h_{r}\right) E\left[\min \left\{Q, z Q_{2}\right\}\right] \\
& -b_{r} \bar{x} .
\end{aligned}
$$

The first two terms represent the normal working state of the cheaper supplier and the next two terms refer to the situation where the cheaper supplier is disrupted. The final term is independent of the risk of supply uncertainty. We derive an alternative representation of the retailer's profit function as follows:

$$
\begin{aligned}
\Pi_{r c}(Q)= & \alpha\left((1-\phi)\left(p-h_{r}\right)+b_{r}\right)\left\{\int_{c}^{\frac{Q-Q_{1}}{Q_{2}}}\left(\int_{l}^{Q_{1}+z Q_{2}} x f(x) \mathrm{d} x+\int_{Q_{1}+z Q_{2}}^{u}\left(Q_{1}+z Q_{2}\right) f(x) \mathrm{d} x\right)\right. \\
& \left.\times h(z) \mathrm{d} z+\int_{\frac{Q-Q_{1}}{Q_{2}}}^{d}\left(\int_{l}^{Q} x f(x) \mathrm{d} x+\int_{Q}^{u} Q f(x) \mathrm{d} x\right) h(z) \mathrm{d} z\right\}+(1-\alpha)\left((1-\phi)\left(p-h_{r}\right)+b_{r}\right) \\
& \times\left\{\int_{c}^{\frac{Q}{Q_{2}}}\left(\int_{l}^{z Q_{2}} x f(x) \mathrm{d} x+\int_{z Q_{2}}^{u} z Q_{2} f(x) \mathrm{d} x\right) h(z) \mathrm{d} z+\int_{\frac{Q}{Q_{2}}}^{d}\left(\int_{l}^{Q} x f(x) \mathrm{d} x+\int_{Q}^{u} Q f(x) \mathrm{d} x\right)\right. \\
& \times h(z) \mathrm{d} z\}-\alpha\left(w_{m}+c_{r}-(1-\phi) h_{r}\right)\left\{\int_{c}^{\frac{Q-Q_{1}}{Q_{2}}}\left(Q_{1}+z Q_{2}\right) h(z) \mathrm{d} z+\int_{\frac{Q-Q_{1}}{Q_{2}}}^{d} Q h(z) \mathrm{d} z\right\} \\
& -(1-\alpha)\left(w_{m}+c_{r}-(1-\phi) h_{r}\right)\left\{\int_{c}^{\frac{Q}{Q_{2}}} z Q_{2} h(z) \mathrm{d} z+\int_{\frac{Q}{Q_{2}}}^{d} Q h(z) \mathrm{d} z\right\}-b_{r} \bar{x} .
\end{aligned}
$$

The retailer's optimal order quantity $Q^{*}$ under the spanning revenue sharing contract is characterized in the following theorem.

Theorem 5.1. The retailer's expected profit function $\Pi_{r c}(Q)$ is concave in $Q$ and the optimal order quantity $Q^{*}$ is given by

$$
Q^{*}=F^{-1}\left(\frac{(1-\phi) p+b_{r}-w_{m}-c_{r}}{(1-\phi)\left(p-h_{r}\right)+b_{r}}\right) .
$$

From (5.3) we find that the retailer's optimal order quantity is an increasing function of the retail price $p$ and a decreasing function of its purchasing cost $w_{m}$ and treating cost $c_{r}$. Also, the order quantity $Q^{*}$ does not depend directly on the cheaper supplier's disruption probability.

The manufacturer's expected profit function is given by

$$
\begin{aligned}
\Pi_{m c}\left(Q_{1}, Q_{2}\right)= & \alpha \phi_{m}\left(p-h_{r}\right) E\left[\min \left\{x, Q, Q_{1}+z Q_{2}\right\}\right]+\alpha\left(w_{m}-c_{m}+\phi_{m} h_{r}-h_{m}\right) \\
& \times E\left[\min \left\{Q, Q_{1}+z Q_{2}\right\}\right]+(1-\alpha) \phi_{m}\left(p-h_{r}\right) E\left[\min \left\{x, Q, z Q_{2}\right\}\right] \\
& +(1-\alpha)\left(w_{m}-c_{m}+\phi_{m} h_{r}-h_{m}\right) E\left[\min \left\{Q, z Q_{2}\right\}\right]-\alpha\left(w_{s 1}-h_{m}\right) \\
& \times Q_{1}-\left(w_{s 2}-h_{m}\right) \bar{z} Q_{2} .
\end{aligned}
$$

An equivalent representation of the manufacturer's expected profit function is given by

$$
\begin{aligned}
\Pi_{m c}\left(Q_{1}, Q_{2}\right)= & \alpha \phi_{m}\left(p-h_{r}\right)\left\{\int_{c}^{\frac{Q-Q_{1}}{Q_{2}}}\left(\int_{l}^{Q_{1}+z Q_{2}} x f(x) \mathrm{d} x+\int_{Q_{1}+z Q_{2}}^{u}\left(Q_{1}+z Q_{2}\right) f(x) \mathrm{d} x\right)\right. \\
& \left.\times h(z) \mathrm{d} z+\int_{\frac{Q^{c}-Q_{1}}{Q_{2}}}^{d}\left(\int_{l}^{Q^{c}} x f(x) \mathrm{d} x+\int_{Q^{c}}^{u} Q^{c} f(x) \mathrm{d} x\right) h(z) \mathrm{d} z\right\}+(1-\alpha) \phi_{m}\left(p-h_{r}\right) \\
& \times\left\{\int_{c}^{\frac{Q}{Q_{2}}}\left(\int_{l}^{z Q_{2}} x f(x) \mathrm{d} x+\int_{z Q_{2}}^{u} z Q_{2} f(x) \mathrm{d} x\right) h(z) \mathrm{d} z+\int_{\frac{Q}{Q_{2}}}^{d}\left(\int_{l}^{Q} x f(x) \mathrm{d} x+\int_{Q}^{u} Q f(x) \mathrm{d} x\right)\right.
\end{aligned}
$$




$$
\begin{aligned}
& \times h(z) \mathrm{d} z\}+\alpha\left(w_{m}-c_{m}+\phi_{m} h_{r}-h_{m}\right)\left\{\int_{c}^{\frac{Q-Q_{1}}{Q_{2}}}\left(Q_{1}+z Q_{2}\right) h(z) \mathrm{d} z+\int_{\frac{Q-Q_{1}}{Q_{2}}}^{d} Q h(z) \mathrm{d} z\right\} \\
& +(1-\alpha)\left(w_{m}-c_{m}+\phi_{m} h_{r}-h_{m}\right)\left\{\int_{c}^{\frac{Q}{Q_{2}}} z Q_{2} h(z) \mathrm{d} z+\int_{\frac{Q}{Q_{2}}}^{d} Q h(z) \mathrm{d} z\right\}-\alpha\left(w_{s 1}-h_{m}\right) Q_{1} \\
& -\left(w_{s 2}-h_{m} \bar{z}\right) Q_{2} .
\end{aligned}
$$

Due to complexity, the concavity of $\Pi_{m c}\left(Q_{1}, Q_{2}\right)$ with respect to $Q_{1}$ and $Q_{2}$ can not be proved analytically. The following proposition explores the manufacturer's optimal order quantities assuming that $\Pi_{m c}$ is concave.

Proposition 5.2. Under the SRS contract, the manufacturer's optimal order quantities $Q_{1}^{*}$ and $Q_{2}^{*}$ satisfy the equations:

$$
\int_{c}^{\frac{Q-Q_{1}^{*}}{Q_{2}^{*}}} \bar{F}\left(Q_{1}^{*}+z Q_{2}^{*}\right) h(z) \mathrm{d} z=\left(\frac{w_{s 1}-h_{m}}{\phi_{m}\left(p-h_{r}\right)}\right)-\frac{\left(w_{m}-c_{m}+\phi_{m} h_{r}-h_{m}\right)}{\phi_{m}\left(p-h_{r}\right)} H\left(\frac{Q-Q_{1}^{*}}{Q_{2}^{*}}\right)
$$

and

$$
\begin{aligned}
& \alpha \int_{c}^{\frac{Q-Q_{1}^{*}}{Q_{2}^{*}}} z \bar{F}\left(Q_{1}^{*}+z Q_{2}^{*}\right) h(z) \mathrm{d} z+(1-\alpha) \int_{c}^{\frac{Q}{Q_{2}^{*}}} z \bar{F} z Q_{2}^{*} h(z) \mathrm{d} z \\
& \quad=\frac{\left(w_{s 2}-h_{m}\right) \bar{z}}{\phi_{m}\left(p-h_{r}\right)}-\frac{\left(w_{m}-c_{m}+\phi_{m} h_{r}-h_{m}\right)}{\phi_{m}\left(p-h_{r}\right)}\left[\alpha \int_{c}^{\frac{Q-Q_{1}^{*}}{Q_{2}^{*}}} z h(z) \mathrm{d} z+(1-\alpha) \int_{c}^{\frac{Q}{Q_{2}^{*}}} z h(z) \mathrm{d} z\right] .
\end{aligned}
$$

The expected profit $\Pi_{s 2 c}$ of the expensive supplier is given by

$$
\begin{aligned}
\Pi_{s 2 c}= & \alpha \phi_{s 2}\left(p-h_{r}\right) E\left[\min \left\{x, Q, Q_{1}+z Q_{2}\right\}\right]+\alpha \phi_{s 2} h_{r} E\left[\min \left\{Q, Q_{1}+z Q_{2}\right\}\right] \\
& +(1-\alpha) \phi_{s 2}\left(p-h_{r}\right) \times E\left[\min \left\{x, Q, z Q_{2}\right\}\right]+(1-\alpha) \phi_{s 2} h_{r} E\left[\min \left\{Q, z Q_{2}\right\}\right] \\
& +\left(w_{s 2} \bar{z}-c_{s 2}\right) Q_{2} .
\end{aligned}
$$

The expected profit $\Pi_{s 1 c}$ of the cheaper supplier is given by

$$
\begin{aligned}
\Pi_{s 1 c}= & \alpha \phi_{s 1}\left(p-h_{r}\right) E\left[\min \left\{x, Q, Q_{1}+z Q_{2}\right\}\right]+\alpha \phi_{s 1} h_{r} E\left[\min \left\{Q, Q_{1}+z Q_{2}\right\}\right] \\
& +(1-\alpha) \phi_{s 1}\left(p-h_{r}\right) \times E\left[\min \left\{x, Q, z Q_{2}\right\}\right]+(1-\alpha) \phi_{s 1} h_{r} E\left[\min \left\{Q, z Q_{2}\right\}\right] \\
& +\alpha\left(w_{s 1}-c_{s 1}\right) Q_{1}+(1-\alpha)\left(h_{s 1}-c_{s 1}\right) Q_{1} .
\end{aligned}
$$

We now obtain the conditions under which the supply chain is coordinated with the spanning revenue sharing contract.

Theorem 5.3. Under the voluntary compliance, the SRS contract with the wholesale prices

$$
\begin{aligned}
& w_{m}=c_{m}+h_{m}-\phi_{m} h_{r}-\frac{c_{m}+c_{r}+h_{m}-h_{r}}{p+b_{r}-h_{r}} \times \phi_{m}\left(p-h_{r}\right) \\
& w_{s 2}=h_{m}+\frac{c_{s 2}-h_{m} \bar{z}}{\bar{z}\left(p+b_{r}-h_{r}\right)} \times \phi_{m}\left(p-h_{r}\right) \\
& w_{s 1}=h_{m}+\frac{\alpha\left(c_{s 1}-h_{m}\right)-(1-\alpha)\left(h_{s 1}-c_{s 1}\right)}{\alpha\left(p+b_{r}-h_{r}\right)} \times \phi_{m}\left(p-h_{r}\right)
\end{aligned}
$$

achieves channel coordination. 
Although the retailer and the manufacturer are free to make their individual decisions under the SRS contract, if the parameters $\left(w_{i}, \phi_{i}\right)$ of the SRS contract conform to equations (5.10) to (5.12), then the optimal orders $Q^{*}, Q_{1}^{*}$, and $Q_{2}^{*}$ will correspond to $Q^{c}, Q_{1}^{c}$, and $Q_{2}^{c}$ respectively. From equations (5.10) to (5.12), we can observe that the wholesale price $w_{i}$ is a function of the retailer's revenue sharing ratio $\phi_{i}$. So, we concentrate on how to calculate $\phi_{i}$ in the SRS contract. Once $\phi_{i}$ is calculated, then the wholesale price $w_{i}$ can be estimated immediately from equations (5.10) to (5.12). With this value of $w_{i}$, the SRS contact coordinates the supply chain irrespective of the adopted value of $\phi_{i}$ i.e., $\Pi_{d c}\left(Q^{*}, Q_{1}^{*}, Q_{2}^{*}\right)=\Pi_{c}\left(Q^{c}, Q_{1}^{c}, Q_{2}^{c}\right)$ where $\Pi_{d c}$ denotes total system profit in the decentralized model under the SRS contract. These observations are used to solve the problem of individual participation. However, the maximum profit of the SC can be assured by adopting the SRS contract with appropriate parameters. This contract is desirable only when the individual profits of all the supply chain entities are higher than those under the decentralized scenario without the SRS contract, as discussed in Section 4.2. In other words, to participate in the contract agreement, achieving win-win outcome for all the supply chain entities is a key requirement. Hence, under the assumption that the SRS contract coordinates the SC i.e., equations (5.10) to (5.12) are fulfilled, to achieve a win-win outcome, the contract makes sure that the following conditions hold:

$$
\begin{aligned}
& \Pi_{r c}>\Pi_{r d} \text { i.e., } \quad \phi_{s 1}+\phi_{s 2}+\phi_{m}=\phi<\left(1-\frac{\frac{\Pi_{r d}+b r \bar{x}}{S_{1}-S_{2} S_{3}}-b r}{p-h_{r}}\right) ; \\
& \Pi_{m c}>\Pi_{m d} \text { i.e., } \quad \phi_{m}>\frac{\Pi_{m d}}{(p-h r)\left(S_{1}-S_{2} S_{3}-\alpha Q_{1} S_{4}-\frac{c_{s 2}-h_{m} \bar{z}}{p+b_{r}-h_{r}} Q_{2}\right)} ; \\
& \Pi_{s 2 c}>\Pi_{s 2 d} \quad \text { i.e., } \quad \phi_{s 2}>\frac{\Pi_{s 2 d}-\left(w_{s 2} \bar{z}-c_{s 2}\right) Q_{2}}{\left(p-h_{r}\right) S_{1}+h_{r} S_{2}} ; \quad \text { and } \\
& \Pi_{s 1 c}>\Pi_{s 1 d} \quad \text { i.e., } \quad \phi_{s 1}>\frac{\Pi_{s 1 d}-\alpha\left(w_{s 1}-c_{s 1}\right) Q_{1}-(1-\alpha)\left(h_{s 1}-c_{s 1}\right) Q_{1}}{\left(p-h_{r}\right) S_{1}+h_{r} S_{2}} ;
\end{aligned}
$$

where $S_{1}=\alpha E\left[\min \left\{x, Q, Q_{1}+z Q_{2}\right\}\right]+(1-\alpha) E\left[\min \left\{x, Q, z Q_{2}\right\}\right]$, the total expected sales; $S_{2}=\alpha E\left[\min \left\{Q, Q_{1}+z Q_{2}\right\}\right]+(1-\alpha) E\left[\min \left\{Q, z Q_{2}\right\}\right]$, the total expected on-hand inventory; $S_{3}=\frac{\left(c_{m}+c_{r}+h_{m}-h_{r}\right)}{\left(p+b_{r}-h_{r}\right)}$ and $S_{4}=\frac{\alpha\left(c_{s 1}-h_{m}\right)+(1-\alpha)\left(c_{s 1}-h_{s 1}\right.}{\alpha\left(p+b_{r}-h_{r}\right)}$.

To sum up, if we adopt the SRS contract $\left(w_{i}, \phi_{i}\right)$ where the revenue sharing ratio $\phi_{i}$ satisfies equations (5.13) to (5.16) and the wholesale price $w_{i}$ is obtained from equations (5.10) to (5.12), then the contract is acceptable to all SC entities and the maximum profit of the SC is attained. As any value of $\phi_{i}$ which satisfies equations (5.13) to (5.16) is acceptable, the adaptation of $\phi_{i}$ depends on the relative bargaining power of the SC entities.

\section{NumericAl EXAMPLE}

A numerical study is conducted in this section to illustrate the developed model. The random demand $x$ is assumed to be uniformly distributed over $[l, u], l \leq x \leq u$, with mean $\bar{x}=500$ and standard deviation $\sigma_{x}=500 / \sqrt{3}$. The production yield of the expensive raw-material supplier is assumed to follow uniform distribution with mean $\bar{z}=0.77$ and standard deviation $\sigma_{z}=0.06$. The exogenous parameter-values are set as follows: $p=130, b_{r}=5, h_{r}=15, c_{r}=5, c_{m}=15, h_{m}=5, c_{s 1}=20, c_{s 2}=40, h_{s 1}=10$, probability of disruption $1-\alpha=0.2$ in appropriate units.

For the above set of values, the concavity of the expected profit function $\Pi_{c}\left(Q_{1}, Q_{2}\right)$ with respect to $Q_{1}$ and $Q_{2}$ is checked graphically as shown in Figure 2. Also we have, from Theorem 4.1, $\Pi_{c}\left(Q, Q_{1}, Q_{2}\right)$ is concave in $Q$. Therefore, we can conclude that $\Pi_{c}\left(Q, Q_{1}, Q_{2}\right)$ is jointly concave in $Q, Q_{1}$ and $Q_{2}$ in the centralized model. Now, for the same data set, under spanning revenue sharing contract, the manufacturer's profit function $\Pi_{m c}\left(Q_{1}, Q_{2}\right)$ is jointly concave in $Q_{1}$ and $Q_{2}$, which can be checked graphically as shown in Figure 3.

Optimal decisions and the expected profits of the benchmark models and the spanning revenue sharing model are shown in Table 1 . Here $\Pi$ stands for the expected total profit of the supply chain irrespective of different 


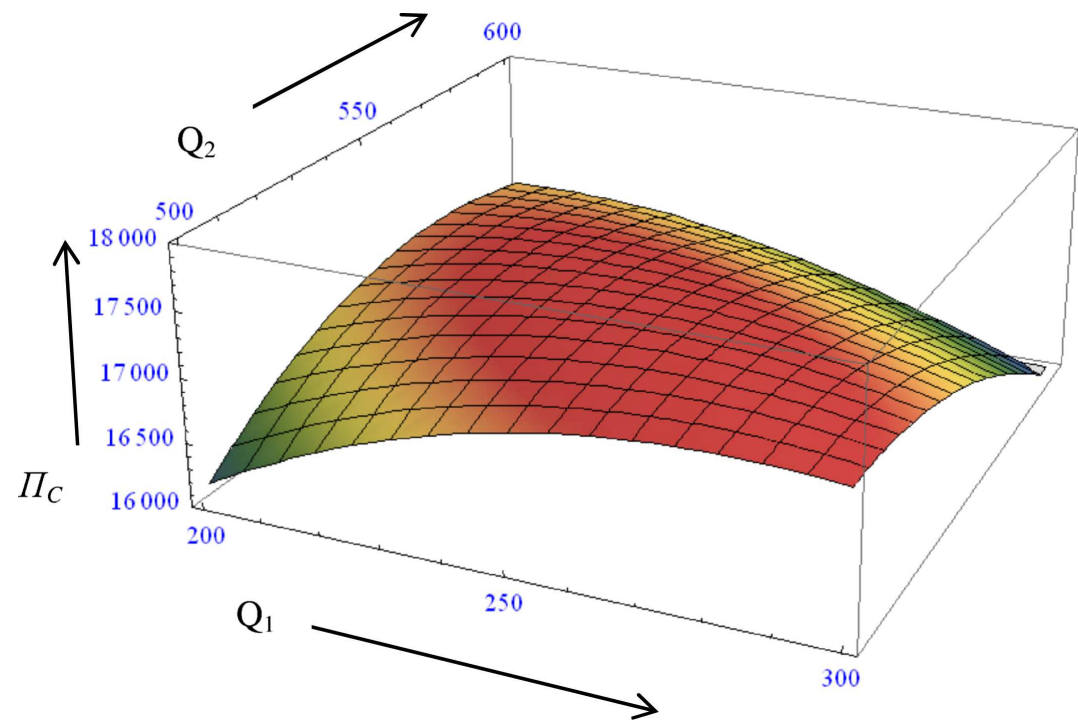

Figure 2. Concavity of $\Pi_{c}\left(Q_{1}, Q_{2}\right)$.

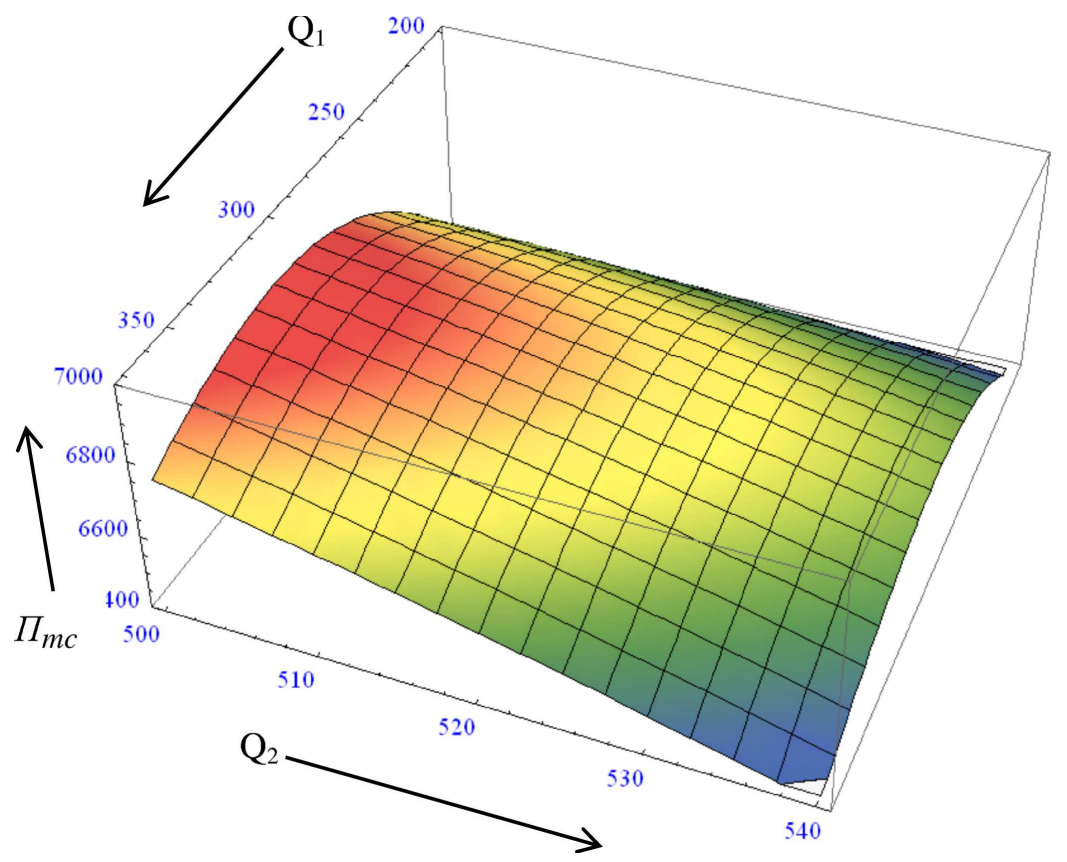

Figure 3. Concavity of $\Pi_{m c}\left(Q_{1}, Q_{2}\right)$ under contract. 
TABLE 1. Optimal decisions and expected profits under different scenarios.

\begin{tabular}{llllllllllll}
\hline \hline Model & $Q$ & $Q_{1}$ & $Q_{2}$ & $\Pi_{s 1}$ & $\Pi_{s 2}$ & $\Pi_{m}$ & $\Pi_{r}$ & $\Pi$ & $w_{s 1}$ & $w_{s 2}$ & $w_{m}$ \\
\hline Centralized & 669 & 259 & 528 & & - & - & - & 17234 & - & - & - \\
\hline Decentralized & 333 & 89 & 317 & 1247 & 1573 & 5362 & 4047 & 12230 & 40 & 60 & 90 \\
\hline Coordinated & 669 & 259 & 528 & 2498 & 2824 & 6613 & 5299 & 17234 & 10.86 & 20.73 & 11.40 \\
\hline
\end{tabular}

kinds of scenario. Table 1 shows that the optimal order quantities in the decentralized benchmark model are less than their counterparts in the centralized benchmark model which supports Theorem 4.5. Once the optimal order quantities of the retailer and the manufacturer are derived then we can obtain the minimum value of $\phi_{i}$ from equations(5.14) to (5.16) and the maximum value of their sum i.e., $\phi_{s 1}+\phi_{s 2}+\phi_{m}=\phi$ from equation (5.13). When the retailer's revenue sharing ratio $\phi_{i}$ is obtained, the consequent wholesale price $w_{i}$ can be derived from equations (5.10) to (5.12).

Theorem 5.3 and related discussion show that the total profit of the SC under SRS contract is the same as that of the centralized model irrespective of the value of $\phi_{i}$. But how to allocate the increased profit among the supply chain entities depends on $\phi_{i}$ 's. From the test results we find that if the conditions in Theorem 5.3 are satisfied i.e., the supply chain is coordinated, then for $\phi_{m}=0.3497, \phi_{s 2}=0.2844, \phi_{s 1}=0.0899$, all the supply chain members earn the same amount of additional profit due to spanning revenue sharing contract, compared to the decentralized benchmark scenario. From Table 1, we find that the optimal order quantities of the retailer and the manufacturer in the spanning revenue sharing contract are equal to the order of the centralized system. Moreover, we find that the wholesale prices of the suppliers and the manufacturer under the spanning revenue sharing contract are less than their counterparts in price-only contract.

If $\phi_{m}$ is specified at its lower bound 0.2835 , then the manufacturer's expected profit is the same as that of the decentralized benchmark scenario. Similarly, if $\phi_{s 1}$ and $\phi_{s 2}$ are specified at the lower bounds 0.2836 and 0.0712 , respectively the expected profits of both the suppliers are the same as that of the decentralized benchmark scenario. On the contrary, if $\phi$ is specified at its upper bound 0.8826 , then the retailer's expected profit is obtained same as that of the decentralized benchmark scenario and the additional benefit goes to the manufacturer and the two suppliers depending on the values of $\phi_{i}$. Any value below the lower limit of $\phi_{i}$ is not acceptable, since there may be a situation where a chain member is worse off by taking part into the proposed contract. Clearly, if the upstream members do not receive appropriate compensation from the retailer, they may not be interested to reduce their wholesale prices. Also, the retailer may not propose the revenue sharing contract if the total revenue sharing ratio crosses its upper bound.

As expected, profits of all the members and the whole supply chain decrease as the demand randomness increases [2]. This is because bad demand forecasting results in the whole system becoming worse off. Due to increase of uncertainty $\left(\sigma_{x}\right)$ in market demand, the retailer should increase the on-hand inventory level so that the risk of stock-out of the final product decreases. So, the order quantity at all the stages (retailer and manufacturer) will increase if $\sigma_{x}$ increases [2]. This may increase the risk of over-stocking and decrease the system profit. The results are summarized in Table 2 .

In order to examine how the channel members' decisions are affected by supply disruption and yield uncertainty, we change the cheaper supplier's disruption probability $(1-\alpha)$ in the range $[0.4,0.7]$. As the production yield of the expensive raw-material supplier is assumed to follow uniform distribution with mean $\bar{z}=0.77$ then the standard deviation $\sigma_{z}$ can vary within the range $[0,0.1328]$ and we assume that the standard deviation $\sigma_{z}$ takes five different values from its range. The optimal decisions of the retailer and the manufacturer in the decentralized model under both revenue sharing contract and price-only contract are shown in Table 3. As mentioned by Chopra et al. [12], if the growth in supply risk comes from increased yield uncertainty of the expensive supplier then the best mitigation strategy is to increase the use of the cheaper supplier. From Table 3 we find that when the growth in supply risk occurs due to increase in yield risk at the expensive supplier, the 
TABLE 2. Optimal decisions and expected profits under contract when demand variance varies.

\begin{tabular}{lllllllll}
\hline \hline$\sigma_{x}$ & $Q^{*}$ & $Q_{1}^{*}$ & $Q_{2}^{*}$ & $\Pi_{s 1 c}$ & $\Pi_{s 2 c}$ & $\Pi_{m c}$ & $\Pi_{r c}$ & $\Pi_{d c}$ \\
\hline$\frac{425}{\sqrt{3}}$ & 653 & 248 & 520 & 2349 & 3282 & 7594 & 6128 & 19354 \\
\hline$\frac{450}{\sqrt{3}}$ & 659 & 252 & 523 & 2257 & 3118 & 7287 & 5986 & 18650 \\
\hline$\frac{475}{\sqrt{3}}$ & 664 & 255 & 525 & 2168 & 2952 & 6980 & 5845 & 17946 \\
\hline$\frac{500}{\sqrt{3}}$ & 669 & 259 & 528 & 2079 & 2783 & 6669 & 5702 & 17234 \\
\hline$\frac{525}{\sqrt{3}}$ & 674 & 262 & 531 & 1993 & 2613 & 6357 & 5660 & 16523 \\
\hline$\frac{550}{\sqrt{3}}$ & 679 & 265 & 534 & 1907 & 2441 & 6044 & 5417 & 15811 \\
\hline$\frac{575}{\sqrt{3}}$ & 684 & 268 & 537 & 1823 & 2268 & 5730 & 5274 & 15097 \\
\hline
\end{tabular}

TABLE 3. Optimal decisions and total expected profits under SRS and price-only contracts when yield variance $\sigma_{z}$ and probability of disruption $(1-\alpha)$ vary.

\begin{tabular}{llllllllll}
\hline \hline \multicolumn{2}{c}{ Risk term } & \multicolumn{4}{c}{ SRS contract } & \multicolumn{3}{c}{ Price-only contract } \\
\hline $1-\alpha$ & $\sigma_{z}$ & $Q^{*}$ & \multicolumn{1}{c}{$Q_{1}^{*}$} & $Q_{2}^{*}$ & $\Pi_{d c}$ & $Q^{d}$ & $Q_{1}^{d}$ & $Q_{2}^{d}$ & $\Pi_{d}$ \\
\hline 0.4 & 0.01 & 545 & 30 & 669 & 14291 & 333 & 10 & 419 & 10783 \\
& 0.04 & 594 & 104 & 633 & 14826 & 333 & 38 & 383 & 10767 \\
& 0.07 & 633 & 161 & 601 & 15202 & 333 & 62 & 352 & 10717 \\
& 0.10 & 664 & 207 & 572 & 15468 & 333 & 82 & 325 & 10647 \\
& 0.13 & 691 & 244 & 546 & 15655 & 333 & 100 & 302 & 10566 \\
\hline 0.5 & 0.01 & 541 & 21 & 673 & 14178 & 333 & 8 & 421 & 10469 \\
& 0.04 & 583 & 75 & 649 & 14440 & 333 & 31 & 391 & 10333 \\
& 0.07 & 618 & 119 & 626 & 14608 & 333 & 52 & 364 & 10178 \\
& 0.10 & 648 & 157 & 604 & 14704 & 333 & 71 & 340 & 10013 \\
& 0.13 & 675 & 189 & 583 & 14745 & 333 & 87 & 319 & 9846 \\
\hline 0.6 & 0.01 & 538 & 13 & 677 & 14108 & 333 & 7 & 423 & 10170 \\
& 0.04 & 575 & 50 & 662 & 14192 & 333 & 27 & 397 & 9948 \\
& 0.07 & 608 & 80 & 646 & 14212 & 333 & 45 & 373 & 9714 \\
& 0.10 & 637 & 108 & 630 & 14181 & 333 & 62 & 351 & 9475 \\
& 0.13 & 664 & 132 & 613 & 14105 & 333 & 77 & 332 & 9236 \\
\hline 0.7 & 0.01 & 537 & 6 & 680 & 14069 & 333 & 6 & 425 & 9879 \\
& 0.04 & 571 & 22 & 673 & 14049 & 333 & 23 & 402 & 9593 \\
& 0.07 & 603 & 37 & 664 & 13979 & 333 & 40 & 380 & 9298 \\
& 0.10 & 632 & 51 & 654 & 13864 & 333 & 55 & 360 & 8999 \\
& 0.13 & 658 & 65 & 642 & 13707 & 333 & 69 & 342 & 8701 \\
\hline & & & & & & & & &
\end{tabular}

manufacturer increases the use of the cheaper supplier and decreases the use of the expensive supplier whether the disruption risk $(1-\alpha)$ of the cheaper supplier is low or high under SRS contract scenario. The manufacturer increases its order quantity at the cheaper supplier more rapidly than it decreases its order quantity at the expensive supplier. As yield risk of one supplier increases, the manufacturer increases utilization of the other supplier. By doing so, the manufacturer is able to mitigate the yield risk of the expensive supplier with the help of the cheaper supplier, which helps the manufacturer to recover from worse off. Similar arguments hold, if the growth in supply risk comes from increased disruption probability of the cheaper supplier.

In the decentralized model with price-only contract too the manufacturer increases the use of the cheaper supplier and decreases the use of the expensive supplier as the production yield's standard deviation $\sigma_{z}$ of the 
expensive supplier increases. It states that as the production yield's uncertainty increases, the manufacturer orders extra units from the cheaper supplier and cuts down the order of the expensive supplier. Since the retailer takes its decision individually in this scenario, it has no incentive to help the manufacturer to mitigate the expensive supplier's yield uncertainty through increasing the order quantity. Therefore, the retailer places unchanged order to the manufacturer to optimize its own objective function. However, the manufacturer realizes this fact and increases its order quantity at the cheaper supplier more slowly than it decreases its order quantity at the expensive supplier. As a result, the expected sales of the product decreases and it directly reduces the entire supply chain's profit as shown in Table 3.

Our general intuition is that the channel performance should increase as the production yield randomness decreases, which has happened for the decentralized benchmark model. However, in the decentralized model under SRS contract, we notice a different result. Table 3 shows that, for a lower disruption risk of the cheaper supplier $((1-\alpha)=0.5$, or less), as the yield randomness increases, the entire supply chain's profit also increases. For $(1-\alpha)=0.6$, the expected profit of the system first increases and then decreases as $\sigma_{z}$ increases. This result is consistent with the result given in [21]. For a higher disruption risk of the cheaper supplier $((1-\alpha)=0.7$ or more), as the yield randomness increases, the channel profit decreases. This result begs proper explanation to answer the following question: why and how does the increased production yield of an upstream supplier enhance the whole system's efficiency in terms of profit for a lower disruption risk $((1-\alpha)=0.5$ or less $)$ but follows our general intuition for a higher disruption risk $((1-\alpha)=0.7$ or more $)$ ? From our computational results, we find that, when the disruption risk is lower $((1-\alpha)=0.5$ or 0.4$)$, the SRS contract can hedge the increased yield uncertainty by decreasing the multiple marginalization effects and incentivizing the retailer to order more to satisfy more customer demand. However, if the disruption risk is too high $((1-\alpha)=0.7$ or more $)$ then the SRS contract is unable to hedge other risk that comes from increased yield uncertainty. So, as the yield randomness increases, the entire supply chain's profit decreases. For $(1-\alpha)=0.6$ the SRS contract can hedge the increased yield uncertainty up to a threshold value $\left(\sigma_{z}=0.07\right)$. When the yield uncertainty exceeds the threshold value, the SRS contract can't hedge the yield uncertainty any more.

In the decentralized model under both spanning revenue sharing contract and price-only contract, the optimal ordering policies of the retailer and the manufacturer for different values of the cheaper supplier's disruption probability $(1-\alpha)$ are shown in Table 3. For a fixed value of $\sigma_{z}$, we explore that as the disruption probability $(1-\alpha)$ increases, the retailer orders less from the manufacturer to hedge the associated risk (as the chance of selling a product becomes lesser with higher uncertainty)under spanning revenue sharing contract. Table 3 illustrates that an increase in the cheaper supplier's disruption probability $(1-\alpha)$ encourages the manufacturer to increase the use of the expensive supplier to mitigate disruption risk, which is consistent with the results given in [12]. We also examine the effect of $(1-\alpha)$ on the supply chain's optimal expected profits as shown in Table 3. As expected, the entire system's expected profit decreases if probability of disruption $(1-\alpha)$ increases under both revenue sharing contract and price-only contract.

We now plot "\% profit gain" of the retailer, the manufacturer, the cheaper supplier, the expensive supplier and the total supply chain, along vertical axis, by $\Pi_{i} \%$ which is calculated as $\Pi_{i} \%=100 \times\left(\Pi_{i c}-\Pi_{i d}\right) / \Pi_{i d}$ for $i \in(r, m, s 1, s 2)$ to show the percentage increase in profit under spanning revenue sharing contract compared to the corresponding profit with wholesale price-only contract as described in [22]. From Figures 4a and 4b we find that the SRS contract is always beneficial to enhance the expected profit of the entire supply chain, whether growth in risk comes from increased demand uncertainty or increased production yield uncertainty. Figure 4a depicts that, with higher demand uncertainty, the profit gain of the retailer becomes more but for the manufacturer and both the suppliers, it becomes less. This is because a higher demand variance motivates the retailer to increase the on-hand inventory to mitigate demand uncertainty but the other entities have no such incentive as their revenue shares and wholesale prices are independent of demand variance under the proposed contract. Figure 4b depicts the effect of production uncertainty of the expensive supplier on the efficiency of coordination. From Figure 4b, we observe that, with an increase in production uncertainty, the profit gain of all the entities becomes more except the cheaper supplier. 


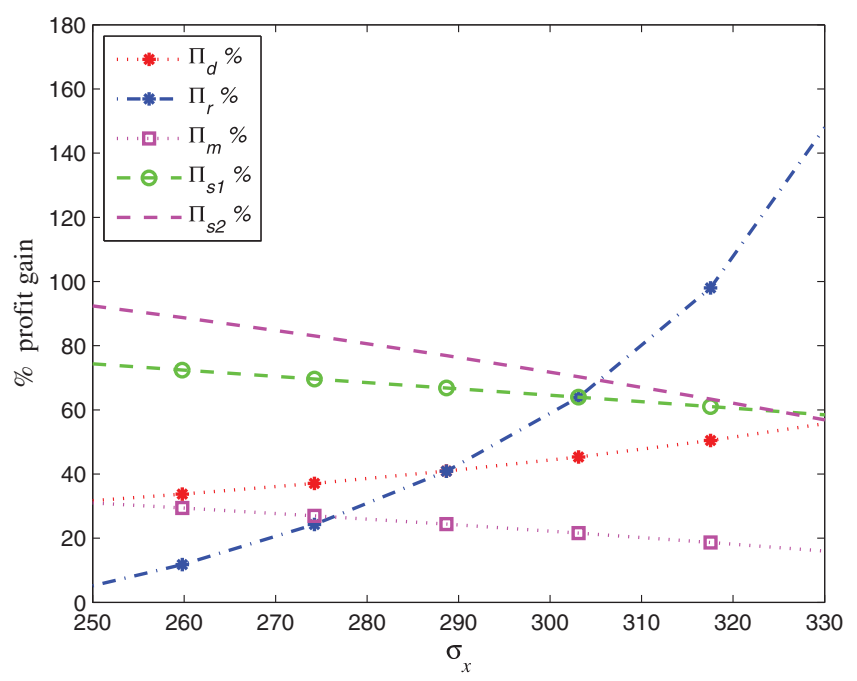

(a)

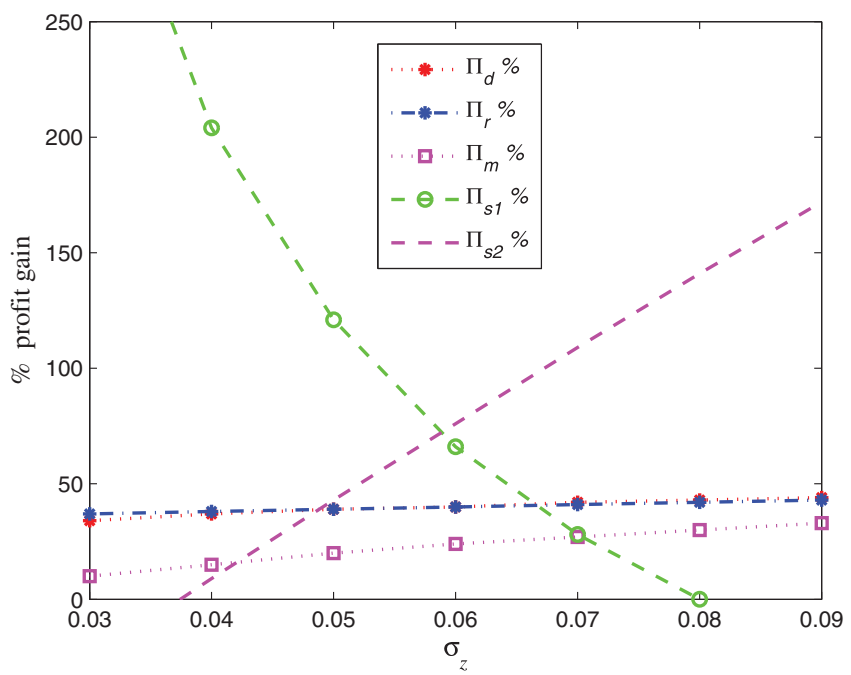

(b)

Figure 4. Performance of coordinated chain with respect to demand and supply uncertainties.

\section{Conclusion}

Supply uncertainty is very common in many companies having global supply networks. Managers are trying to innovate procurement process to mitigate the existing risk in supply chain. They rely on reliable backup resources having sufficient capacity. So far, access of unreliable backup supplier is not used as a mitigation strategy, what we have considered in this study.

We have analyzed the integrated model as the centralized benchmark case and the decentralized model with wholesale price only contract as decentralized benchmark case. Then aiming at how the risk of uncertainties in both supply and demand can be distributed among the supply chain entities, we have introduced a spanning revenue sharing contract into the decentralized system. 
We have explored coordination conditions and elaborated the circumstance under which the contract is desirable to each of the individual members as well as the entire supply chain. Dada et al. [13] have shown that cost dominates reliability when selecting suppliers. In this paper, we have expanded their insights by focusing on the relative use of the two unreliable suppliers. Some managerial implications of our model are as follows:

- If the enhancement in supply uncertainty is mainly due to increase in random yield in production, it is optimal to increase the use of the cheaper supplier. In contrast, if the enhancement in supply uncertainty comes mainly from supply disruption, it is beneficial to over-utilize the expensive supplier who is subject to random yield and under-utilize the cheaper supplier who is prone to disruption.

- It is natural that all the supply chain members sign the proposed contract for its successful implementation. Although this does not mean that, for successful implementation, all the members have to sign the agreement simultaneously.

As a future research direction, one can study a multi-echelon supply chain model where more than one member can dominate the chain instead of allowing the retailer, as we have considered, to control business policies unilaterally. One can also consider the difference in quality between the raw materials produced by the cheaper supplier and the expensive supplier, and develop a model where the yield of the manufacturer depends on the quality of the raw material. Extending the present work to a multi-period model would also be a worthful contribution.

Acknowledgements. The authors are thankful to the editor and the anonymous referees for their valuable comments and suggestions which have improved the quality of the paper significantly. This work was partially supported by University Grants Commission (UGC), Govt. of India, New Delhi (Grant Ref. No. 20/12/2015(ii)EU-V).

\section{Appendix A. Proof of Theorem 4.1}

We have

$$
\begin{aligned}
\frac{\partial \Pi_{c}\left(Q, Q_{1}, Q_{2}\right)}{\partial Q}= & \alpha\left(p+b_{r}-h_{r}\right) \int_{\frac{Q-Q_{1}}{Q_{2}}}^{d}\left(\int_{Q}^{u} f(x) \mathrm{d} x\right) h(z) \mathrm{d} z+(1-\alpha)\left(p+b_{r}-h_{r}\right) \\
& \times \int_{\frac{Q}{Q_{2}}}^{d}\left(\int_{Q}^{u} f(x) \mathrm{d} x\right) h(z) \mathrm{d} z-\alpha\left(c_{m}+c_{r}+h_{m}-h_{r}\right) \int_{\frac{Q-Q_{1}}{Q_{2}}}^{d} h(z) \mathrm{d} z \\
& -(1-\alpha)\left(c_{m}+c_{r}+h_{m}-h_{r}\right) \int_{\frac{Q}{Q_{2}}}^{d} h(z) \mathrm{d} z
\end{aligned}
$$

and

$$
\begin{aligned}
\frac{\partial^{2} \Pi_{c}\left(Q, Q_{1}, Q_{2}\right)}{\partial Q^{2}}= & \alpha \frac{1}{Q_{2}} h\left(\frac{Q-Q_{1}}{Q_{2}}\right)\left\{\left(c_{m}+c_{r}+h_{m}-h_{r}\right)-\left(p+b_{r}-h_{r}\right) \bar{F}(Q)\right\} \\
& +(1-\alpha) \frac{1}{Q_{2}} h\left(\frac{Q}{Q_{2}}\right)\left\{\left(c_{m}+c_{r}+h_{m}-h_{r}\right)-\left(p+b_{r}-h_{r}\right) \bar{F}(Q)\right\} \\
& -\alpha\left(p+b_{r}-h_{r}\right) f(Q) \bar{H}\left(\frac{Q-Q_{1}}{Q_{2}}\right)-(1-\alpha)\left(p+b_{r}-h_{r}\right) \\
& \times f(Q) \bar{H}\left(\frac{Q}{Q_{2}}\right) .
\end{aligned}
$$

From the first order optimality condition $\frac{\partial \Pi_{c}\left(Q, Q_{1}, Q_{2}\right)}{\partial Q}=0$, we obtain the optimal order quantity $Q^{c}$ in the centralized benchmark setting as 


$$
Q^{c}=F^{-1}\left(\frac{p+b_{r}-c_{m}-c_{r}-h_{m}}{p+b_{r}-h_{r}}\right)
$$

Putting (4.3) in (A.2) we get,

$$
\frac{\partial^{2} \Pi_{c}\left(Q, Q_{1}, Q_{2}\right)}{\partial Q^{2}}=-\alpha\left(p+b_{r}-h_{r}\right) f\left(Q^{c}\right) \bar{H}\left(\frac{Q^{c}-Q_{1}}{Q_{2}}\right)-(1-\alpha)\left(p+b_{r}-h_{r}\right) f\left(Q^{c}\right) \bar{H}\left(\frac{Q^{c}}{Q_{2}}\right) \leq 0 .
$$

This proves the theorem.

\section{Appendix B. Proof of Proposition 4.2}

From equation (4.4), we get

$$
\begin{aligned}
\frac{\partial \Pi_{c}\left(Q_{1}, Q_{2}\right)}{\partial Q_{1}}= & \alpha\left(p+b_{r}-h_{r}\right) \int_{c}^{\frac{Q^{c}-Q_{1}}{Q_{2}}}\left(\int_{Q_{1}+z Q_{2}}^{u} f(x) \mathrm{d} x\right) h(z) \mathrm{d} z \\
& -\alpha \times\left(c_{m}+c_{r}+h_{m}-h_{r}\right) \int_{c}^{\frac{Q^{c}-Q_{1}}{Q_{2}}} h(z) \mathrm{d} z-\alpha\left(c_{s 1}-h_{m}\right) \\
& -(1-\alpha)\left(h_{s 1}-c_{s 1}\right) \\
\frac{\partial \Pi_{c}\left(Q_{1}, Q_{2}\right)}{\partial Q_{2}}= & \alpha\left(p+b_{r}-h_{r}\right) \int_{c}^{\frac{Q^{c}-Q_{1}}{Q_{2}}} z\left(\int_{Q_{1}+z Q_{2}}^{u} f(x) \mathrm{d} x\right) h(z) \mathrm{d} z+(1-\alpha)\left(p+b_{r}-h_{r}\right) \\
& \times \int_{c}^{\frac{Q^{c}}{Q_{2}}} z\left(\int_{z Q_{2}}^{u} f(x) \mathrm{d} x\right) h(z) \mathrm{d} z-\alpha\left(c_{m}+c_{r}+h_{m}-h_{r}\right) \int_{c}^{\frac{Q^{c}-Q_{1}}{Q_{2}}} z h(z) \mathrm{d} z \\
& -(1-\alpha)\left(c_{m}+c_{r}+h_{m}-h_{r}\right) \int_{c}^{\frac{Q^{c}}{Q_{2}}} z h(z) \mathrm{d} z+\left(c_{s 2}-h_{m} \bar{z}\right) .
\end{aligned}
$$

From the first order optimality conditions $\frac{\partial \Pi_{c}\left(Q_{1}, Q_{2}\right)}{\partial Q_{1}}=0$ and $\frac{\partial \Pi_{c}\left(Q_{1}, Q_{2}\right)}{\partial Q_{2}}=0$, we see that the order quantities $Q_{1}^{c}$ and $Q_{2}^{c}$ satisfy the following equations:

$$
\begin{aligned}
\int_{c}^{\frac{Q^{c}-Q_{1}^{c}}{Q_{2}^{c}}} & \bar{F}\left(Q_{1}^{c}+z Q_{2}^{c}\right) h(z) \mathrm{d} z=\frac{\alpha\left(c_{s 1}-h_{m}\right)-(1-\alpha)\left(h_{s 1}-c_{s 1}\right)}{\alpha\left(p+b_{r}-h_{r}\right)} \\
& +\frac{\left(c_{m}+c_{r}+h_{m}-h_{r}\right)}{\left(p+b_{r}-h_{r}\right)} H\left(\frac{Q^{c}-Q_{1}^{c}}{Q_{2}^{c}}\right) \\
& \alpha \int_{c}^{\frac{Q^{c}-Q_{1}^{c}}{Q_{2}^{c}}} z \bar{F}\left(Q_{1}^{c}+z Q_{2}^{c}\right) h(z) \mathrm{d} z+(1-\alpha) \int_{c}^{\frac{Q_{c}}{Q_{2}^{c}}} z \bar{F}\left(z Q_{2}^{c}\right) h(z) \mathrm{d} z \\
= & \frac{\left(c_{m}+c_{r}+h_{m}-h_{r}\right)}{\left(p+b_{r}-h_{r}\right)}\left[\alpha \int_{c}^{\frac{Q^{c}-Q_{1}^{c}}{Q_{2}^{c}}} z h(z) \mathrm{d} z+(1-\alpha) \int_{c}^{\frac{Q_{c}}{Q_{2}^{c}}} z h(z) \mathrm{d} z\right] \mathrm{d} z \\
& +\frac{c_{s 2}-h_{m} \bar{z}}{\left(p+b_{r}-h_{r}\right)} .
\end{aligned}
$$




\section{Appendix C. Proof of Theorem 4.3}

We have

$$
\begin{aligned}
\frac{\partial \Pi_{r d}(Q)}{\partial Q}= & \alpha\left(p+b_{r}-h_{r}\right) \int_{\frac{Q-Q_{1}}{Q_{2}}}^{d}\left(\int_{Q}^{u} f(x) \mathrm{d} x\right) h(z) \mathrm{d} z+(1-\alpha)\left(p+b_{r}-h_{r}\right) \\
& \times \int_{\frac{Q}{Q_{2}}}^{d}\left(\int_{Q}^{u} f(x) \mathrm{d} x\right) h(z) \mathrm{d} z-\alpha\left(w_{m}+c_{r}-h_{r}\right) \int_{\frac{Q-Q_{1}}{Q_{2}}}^{d} h(z) \mathrm{d} z \\
& -(1-\alpha)\left(w_{m}+c_{r}-h_{r}\right) \int_{\frac{Q}{Q_{2}}}^{d} h(z) \mathrm{d} z \\
\text { and } \quad \frac{\partial^{2} \Pi_{r d}(Q)}{\partial Q^{2}}= & \alpha \frac{1}{Q_{2}} h\left(\frac{Q-Q_{1}}{Q_{2}}\right)\left\{\left(w_{m}+c_{r}-h_{r}\right)-\left(p+b_{r}-h_{r}\right) \bar{F}(Q)\right\} \\
& +(1-\alpha) \frac{1}{Q_{2}} h\left(\frac{Q}{Q_{2}}\right)\left\{\left(w_{m}+c_{r}-h_{r}\right)-\left(p+b_{r}-h_{r}\right) \bar{F}(Q)\right\} \\
& -\alpha\left(p+b_{r}-h_{r}\right) f(Q) \bar{H}\left(\frac{Q-Q_{1}}{Q_{2}}\right)-(1-\alpha)\left(p+b_{r}-h_{r}\right) \\
& \times f(Q) \bar{H}\left(\frac{Q}{Q_{2}}\right) .
\end{aligned}
$$

From the first order optimality condition $\frac{\partial \Pi_{r d}(Q)}{\partial Q}=0$, we obtain the retailer's optimal order quantity $Q^{d}$ as

$$
Q^{d}=F^{-1}\left(\frac{p+b_{r}-w_{m}-c_{r}}{p+b_{r}-h_{r}}\right)
$$

Putting (4.9) in (C.2) we get,

$$
\frac{\partial^{2} \Pi_{r d}(Q)}{\partial Q^{2}}=-\alpha\left(p+b_{r}-h_{r}\right) f\left(Q^{d}\right) \bar{H}\left(\frac{Q^{d}-Q_{1}}{Q_{2}}\right)-(1-\alpha)\left(p+b_{r}-h_{r}\right) f\left(Q^{d}\right) \bar{H}\left(\frac{Q^{d}}{Q_{2}}\right) \leq 0 .
$$

To show that $Q^{d}$ is a decreasing function of $w_{m}$, we have to show that $\frac{\partial Q^{d}}{\partial w_{m}} \leq 0$.

We have, $F\left(Q^{d}\right)=\left(\frac{p+b_{r}-w_{m}-c_{r}}{p+b_{r}-h_{r}}\right)$. Then $\frac{\partial Q^{d}}{\partial w_{m}}=-f\left(Q^{d}\right)\left(p+b_{r}-h_{r}\right) \leq 0$. By similar argument, it can be shown that $Q^{d}$ is a decreasing function of $c_{r}$.

\section{Appendix D. Proof of Theorem 4.4}

To prove that the manufacturer's profit function is jointly concave in $Q_{1}$ and $Q_{2}$ in the decentralized benchmark model, we have

$$
\begin{gathered}
\frac{\partial \Pi_{m d}\left(Q_{1}, Q_{2}\right)}{\partial Q_{1}}=\alpha\left(w_{m}-c_{m}-h_{m}\right) \int_{c}^{\frac{Q-Q_{1}}{Q_{2}}} h(z) \mathrm{d} z-\alpha\left(w_{s 1}-h_{m}\right) \\
\frac{\partial^{2} \Pi_{m d}\left(Q_{1}, Q_{2}\right)}{\partial Q_{1}^{2}}=-\alpha\left(w_{m}+c_{m}-h_{m}\right) \frac{1}{Q_{2}} h\left(\frac{Q-Q_{1}}{Q_{2}}\right)
\end{gathered}
$$




$$
\begin{aligned}
\frac{\partial \Pi_{m d}\left(Q_{1}, Q_{2}\right)}{\partial Q_{2}}= & \left(w_{m}-c_{m}-h_{m}\right) \int_{c}^{\frac{Q-Q_{1}}{Q_{2}}} z h(z) \mathrm{d} z-\left(w_{s 2}-h_{m}\right) \bar{z} \\
& +(1-\alpha)\left(w_{m}-c_{m}-h_{m}\right) \int_{c}^{\frac{Q}{Q_{2}}} z h(z) \mathrm{d} z \\
\frac{\partial^{2} \Pi_{m d}\left(Q_{1}, Q_{2}\right)}{\partial Q_{2}^{2}}= & -\alpha\left(w_{m}-c_{m}-h_{m}\right) \frac{\left(Q-Q_{1}\right)^{2}}{Q_{2}^{3}} h\left(\frac{Q-Q_{1}}{Q_{2}}\right) \\
\text { and } \quad \frac{\partial^{2} \Pi_{m d}\left(Q_{1}, Q_{2}\right)}{\partial Q_{2} \partial Q_{1}}= & -\alpha\left(w_{m}-c_{m}-h_{m}\right)\left(\frac{Q-w_{m}-c_{m}}{Q_{2}^{2}}\right) h\left(\frac{Q}{Q_{2}^{3}} h\left(\frac{Q}{Q_{2}}\right)\right.
\end{aligned}
$$

The Hessian matrix is

$$
H=\left(\begin{array}{ll}
\frac{\partial^{2} \Pi_{m d}\left(Q_{1}, Q_{2}\right)}{\partial Q_{1}^{2}} & \frac{\partial^{2} \Pi_{m d}\left(Q_{1}, Q_{2}\right)}{\partial Q_{2} \partial Q_{1}} \\
\frac{\partial^{2} \Pi_{m d}\left(Q_{1}, Q_{2}\right)}{\partial Q_{2} \partial Q_{1}} & \frac{\partial^{2} \Pi_{m d}\left(Q_{1}, Q_{2}\right)}{\partial Q_{2}^{2}}
\end{array}\right) .
$$

Clearly we have $\left|H_{1}\right|=-\alpha\left(w_{m}+c_{m}-h_{m}\right) \frac{1}{Q_{2}} h\left(\frac{Q-Q_{1}}{Q^{2}}\right)<0$ and $\left|H_{2}\right|=\alpha(1-\alpha)\left(w_{m}-c_{m}-h_{m}\right)^{2} \frac{Q^{2}}{Q_{2}^{4}} h$ $\left(\frac{Q-Q_{1}}{Q^{2}}\right)>0$. This shows that the hessian matrix is negative definite. Then, from the first order optimality conditions $\frac{\partial \Pi_{m d}\left(Q_{1}, Q_{2}\right)}{\partial Q_{1}}=0$ and $\frac{\partial \Pi_{m d}\left(Q_{1}, Q_{2}\right)}{\partial Q_{2}}=0$, we obtain the optimal solution. Therefore, the manufacturer's order quantities $Q_{1}^{d}$ and $Q_{2}^{d}$ satisfy the following equations:

$$
\begin{gathered}
Q_{1}^{d}=Q-Q_{2}^{d} \times H^{-1}\left(\frac{w_{s 1}-h_{m}}{w_{m}-c_{m}-h_{m}}\right) \\
\alpha \int_{c}^{\frac{Q-Q_{1}^{d}}{Q_{2}^{d}}} z h(z) \mathrm{d} z+(1-\alpha) \int_{c}^{\frac{Q}{Q_{2}^{d}}} z h(z) \mathrm{d} z=\frac{\left(w_{s 2}-h_{m}\right) \bar{z}}{\left(w_{m}-c_{m}-h_{m}\right)} .
\end{gathered}
$$

\section{Appendix E. Proof of Theorem 4.5}

We have $w_{m}>c_{m}+w_{s 2}$ and $w_{s 2}>w_{s 1}$ which imply that $w_{m}>c_{m}+w_{s 1}$. Since $h_{m}<w_{s 1}$, therefore, we have $w_{m}>c_{m}+h_{m}$. Now, comparing (4.9) with (4.3) and using the fact that $w_{m}>c_{m}+h_{m}$, we find that, in the decentralized benchmark model, the retailer's optimal order quantity is strictly less than that in the centralized benchmark model. As the retailer orders less amount for the final product, the order quantity of the manufacturer for raw materials in the decentralized benchmark model is also less than that in the centralized benchmark model, which can be realized by comparing (4.12) and (4.13) with (4.5) and (4.6), respectively. Adding the supply chain members' expected profits, we get $\Pi_{r d}+\Pi_{m d}+\Pi_{s 2 d}+\Pi_{s 1 d}=\Pi_{d}$. It is easy to verify that $\Pi_{c}\left(Q^{c}, Q_{1}^{c}, Q_{2}^{c}\right)>\Pi_{d}\left(Q^{d}, Q_{1}^{d}, Q_{2}^{d}\right)$. Both the supplier's and the manufacturer's individual pricing policies are the reason behind the supply chain's inefficiency in the decentralized benchmark setting.

\section{Appendix F. Proof of Theorem 5.1}

To prove the concavity of the retailer's profit function in the decentralized benchmark model under spanning revenue sharing contract, we have 


$$
\begin{aligned}
\frac{\partial \Pi_{r c}(Q)}{\partial Q}= & \alpha\left((1-\phi)\left(p-h_{r}\right)+b_{r}\right) \int_{\frac{Q-Q_{1}}{Q_{2}}}^{d}\left(\int_{Q}^{u} f(x) \mathrm{d} x\right) h(z) \mathrm{d} z+(1-\alpha) \\
& \times\left((1-\phi)\left(p-h_{r}\right)+b_{r}\right) \int_{\frac{Q}{Q_{2}}}^{d}\left(\int_{Q}^{u} f(x) \mathrm{d} x\right) h(z) \mathrm{d} z-\alpha\left(w_{m}+c_{r}\right. \\
& \left.-(1-\phi) h_{r}\right) \int_{\frac{Q-Q_{1}}{Q_{2}}}^{d} h(z) \mathrm{d} z-(1-\alpha)\left(w_{m}+c_{r}-(1-\phi) h_{r}\right) \int_{\frac{Q}{Q_{2}}}^{d} h(z) \mathrm{d} z \\
\frac{\partial^{2} \Pi_{r c}(Q)}{\partial Q^{2}}= & \alpha \frac{1}{Q_{2}} h\left(\frac{Q-Q_{1}}{Q_{2}}\right)\left\{\left(w_{m}+c_{r}-(1-\phi) h_{r}\right)-\left((1-\phi)\left(p-h_{r}\right)+b_{r}\right) \bar{F}(Q)\right\} \\
& +(1-\alpha) \frac{1}{Q_{2}} h\left(\frac{Q}{Q_{2}}\right)\left\{\left(w_{m}+c_{r}-(1-\phi) h_{r}\right)-\left((1-\phi)\left(p-h_{r}\right)+b_{r}\right) \bar{F}(Q)\right\} \\
& -\alpha\left((1-\phi)\left(p-h_{r}\right)+b_{r}\right) f(Q) \bar{H}\left(\frac{Q-Q_{1}}{Q_{2}}\right)-(1-\alpha)\left((1-\phi)\left(p-h_{r}\right)+b_{r}\right) \\
& \times f(Q) \bar{H}\left(\frac{Q}{Q_{2}}\right) .
\end{aligned}
$$

From the first order optimality condition $\frac{\partial \Pi_{r c}(Q)}{\partial Q}=0$, we obtain the retailer's optimal order quantity $Q^{*}$ as

$$
Q^{*}=F^{-1}\left(\frac{(1-\phi) p+b_{r}-w_{m}-c_{r}}{(1-\phi)\left(p-h_{r}\right)+b_{r}}\right)
$$

Putting (5.3) in (F.2) we get,

$$
\frac{\partial^{2} \Pi_{r c}(Q)}{\partial Q^{2}} \leq 0
$$

To show that $Q^{*}$ is an increasing function of $p$, it is sufficient to show that $\frac{\partial^{2} \Pi_{r c}(Q)}{\partial Q \partial p} \geq 0$.

Now,

$$
\frac{\partial^{2} \Pi_{r c}(Q)}{\partial Q \partial p}=\alpha(1-\phi) \bar{F}(Q) \bar{H}\left(\frac{Q-Q_{1}}{Q_{2}}\right)+(1-\alpha)(1-\phi) \bar{F}(Q) \bar{H}\left(\frac{Q}{Q_{2}}\right) \geq 0
$$

To show that $Q^{*}$ is a decreasing function of $c_{r}$, it is sufficient to show that $\frac{\partial^{2} \Pi_{r c}(Q)}{\partial Q \partial c_{r}} \leq 0$.

Now,

$$
\frac{\partial^{2} \Pi_{r c}(Q)}{\partial Q \partial c_{r}}=-\alpha \int_{\frac{Q-Q_{1}}{Q_{2}}}^{d} h(z) \mathrm{d} z-(1-\alpha) \int_{\frac{Q}{Q_{2}}}^{d} h(z) \mathrm{d} z \leq 0 .
$$

By similar argument it can be shown that $Q^{*}$ is a decreasing function of $w_{m}$.

\section{Appendix G. Proof of Proposition 5.2}

From equation (5.5), we have

$$
\begin{aligned}
\frac{\partial \Pi_{m c}\left(Q_{1}, Q_{2}\right)}{\partial Q_{1}}= & \alpha \phi_{m}\left(p-h_{r}\right) \int_{c}^{\frac{Q-Q_{1}}{Q_{2}}}\left(\int_{Q_{1}+z Q_{2}}^{u} f(x) \mathrm{d} x\right) h(z) \mathrm{d} z-\alpha\left(w_{s 1}-h_{m}\right) \\
& +\alpha\left(w_{m}-c_{m}+\phi_{m} h_{r}-h_{m}\right) \int_{c}^{\frac{Q-Q_{1}}{Q_{2}}} h(z) \mathrm{d} z
\end{aligned}
$$




$$
\begin{aligned}
\frac{\partial \Pi_{m c}\left(Q_{1}, Q_{2}\right)}{\partial Q_{2}}= & \alpha \phi_{m}\left(p-h_{r}\right) \int_{c}^{\frac{Q-Q_{1}}{Q_{2}}} z\left(\int_{Q_{1}+z Q_{2}}^{u} f(x) \mathrm{d} x\right) h(z) \mathrm{d} z \\
& +\alpha\left(w_{m}-c_{m}+\phi_{m} h_{r}-h_{m}\right) \int_{c}^{\frac{Q-Q_{1}}{Q_{2}}} z h(z) \mathrm{d} z \\
& +(1-\alpha) \phi_{m}\left(p-h_{r}\right) \int_{c}^{\frac{Q}{Q_{2}}} z\left(\int_{z Q_{2}}^{u} f(x) \mathrm{d} x\right) h(z) \mathrm{d} z+(1-\alpha) \\
& \times\left(w_{m}-c_{m}+\phi_{m} h_{r}-h_{m}\right) \int_{c}^{\frac{Q}{Q_{2}}} z h(z) \mathrm{d} z+\left(w_{s 2}-h_{m}\right) \bar{z} .
\end{aligned}
$$

From the first order optimality conditions $\frac{\partial \Pi_{m c}\left(Q_{1}, Q_{2}\right)}{\partial Q_{1}}=0$ and $\frac{\partial \Pi_{m c}\left(Q_{1}, Q_{2}\right)}{\partial Q_{2}}=0$, we obtain the optimal solution. The manufacturer's order quantities $Q_{1}^{*}$ and $Q_{2}^{*}$ satisfy the equations:

$$
\begin{aligned}
& \int_{c}^{\frac{Q-Q_{1}^{*}}{Q_{2}^{*}}} \bar{F}\left(Q_{1}^{*}+z Q_{2}^{*}\right) h(z) \mathrm{d} z=\left(\frac{w_{s 1}-h_{m}}{\phi_{m}\left(p-h_{r}\right)}\right)-\frac{\left(w_{m}-c_{m}+\phi_{m} h_{r}-h_{m}\right)}{\phi_{m}\left(p-h_{r}\right)} \\
& \quad \times H\left(\frac{Q-Q_{1}^{*}}{Q_{2}^{*}}\right) \\
& \alpha \int_{c}^{\frac{Q-Q_{1}^{*}}{Q_{2}^{*}}} z \bar{F}\left(Q_{1}^{*}+z Q_{2}^{*}\right) h(z) \mathrm{d} z+(1-\alpha) \int_{c}^{\frac{Q}{Q_{2}^{*}}} z \bar{F}\left(z Q_{2}^{*}\right) h(z) \mathrm{d} z \\
&=\frac{\left(w_{s 2}-h_{m}\right) \bar{z}}{\phi_{m}\left(p-h_{r}\right)}-\frac{\left(w_{m}-c_{m}+\phi_{m} h_{r}-h_{m}\right)}{\phi_{m}\left(p-h_{r}\right)}\left[\alpha \int_{c}^{\frac{Q-Q_{1}^{*}}{Q_{2}^{*}}} z h(z) \mathrm{d} z\right. \\
&\left.\quad+(1-\alpha) \int_{c}^{\frac{Q}{Q_{2}^{*}}} z h(z) \mathrm{d} z\right] .
\end{aligned}
$$

\section{Appendix H. Proof of Theorem 5.3}

Using the supply chain members' optimal decisions of the decentralized model under spanning revenue sharing contract given in Theorem 5.1 and Proposition 5.2, we obtain the conditions such that the supply chain is coordinated. Comparing (4.3) with (5.3), we get

$w_{m}=\frac{\left((1-\phi)\left(p-h_{r}\right)+b_{r}\right)\left(c_{m}+h_{m}\right)-\phi_{m}\left(b_{r} h_{r}+\left(p-h_{r}\right) c_{r}\right)}{\left(1-\phi_{s 2}-\phi_{s 1}\right)\left(p-h_{r}\right)+b_{r}}$. As a result, the retailer orders the amount of the final product which is same as that of the centralized model. Also, comparing Proposition 5.2 with Proposition 4.2, we get $w_{s 2}=h_{m}+\frac{c_{s 2}-h_{m} \bar{z}}{p+b_{r}-h_{r}} \times \frac{\phi_{m}\left(p-h_{r}\right)}{\bar{z}}$ and $w_{s 1}=h_{m}+\frac{\alpha\left(c_{s 1}-h_{m}\right)-(1-\alpha)\left(h_{s 1}-c_{s 1}\right)}{\alpha\left(p+b_{r}-h_{r}\right)}$. Under these two conditions, the manufacturer takes the ordering decisions for raw material, which are same as those of the centralized model. Further, using conditions in equations (5.10) to (5.12), the total expected profit of the decentralized system under spanning revenue sharing contract is $\Pi_{r c}\left(Q^{*}\right)+\Pi_{m c}\left(Q_{1}^{*}, Q_{2}^{*}\right)+\Pi_{s 2 c}+\Pi_{s 1 c}=\Pi_{c}\left(Q^{c}, Q_{1}^{c}, Q_{2}^{c}\right)$.

\section{REFERENCES}

[1] R. Anupindi and R. Akella, Diversification under supply uncertainty. Manage. Sci. 39 (1993) 944-963.

[2] S. Asian and X. Nie, Coordination in supply chains with uncertain demand and disruption risks: existence, analysis, and insights. IEEE Trans. Syst. Man Cybern. Syst. 44 (2014) 1139-1154.

[3] P.D. Berger and A.Z. Zeng, Single versus multiple sourcing in the presence of risks. J. Oper. Res. Soc. 57 (2006) $250-261$.

[4] P.D. Berger, A. Gerstenfeld and A.Z. Zeng, How many suppliers are best? A decision-analysis approach. Omega 32 (2004) $9-15$.

[5] E.V. Bulinskaya, Some results concerning optimum inventory policies. Theory Probab. App. 9 (1964) $389-403$.

[6] G.P. Cachon, Supply chain coordination with contracts. Handbooks Oper. Res. Manage. Sci. 11 (2003) $227-339$. 
[7] G.P. Cachon and M.A. Lariviere, Contracting to assure supply: how to share demand forecasts in a supply chain. Manage. Sci. 47 (2001) 629-646.

[8] T. Chakraborty, S.S. Chauhan and M. Ouhimmou, Mitigating supply disruption with a backup supplier under uncertain demand: competition vs. cooperation. Int. J. Prod. Res. (2019) 1-32.

[9] X. Chen and Z.-J. Shen, An analysis of a supply chain with options contracts and service requirements. IIE Trans. 44 (2012) $805-819$.

[10] K. Chen and T. Xiao, Production planning and backup sourcing strategy of a buyer-dominant supply chain with random yield and demand. Int. J. Syst. Sci. 46 (2015) 2799-2817.

[11] K. Chen and L. Yang, Random yield and coordination mechanisms of a supply chain with emergency backup sourcing. Int. J. Prod. Res. 52 (2014) 4747-4767.

[12] S. Chopra, G. Reinhardt and U. Mohan, The importance of decoupling recurrent and disruption risks in a supply chain. Nav. Res. Logist. 54 (2007) 544-555.

[13] M. Dada, N.C. Petruzzi and L.B. Schwarz, A newsvendor's procurement problem when suppliers are unreliable. Manuf. Serv. Oper. Manage. 9 (2007) 9-32.

[14] M. Fisher, J. Hammond, W. Obermeyer and A. Raman, Configuring a supply chain to reduce the cost of demand uncertainty. Prod. Oper. Manage. 6 (1997) 211-225.

[15] X. Gan, S.P. Sethi and H. Yan, Coordination of supply chains with risk-averse agents. Prod. Oper. Manage. 13 (2004) $135-149$.

[16] Y. Gerchak and Y. Wang, Revenue-sharing vs. wholesale-price contracts in assembly systems with random demand. Prod. Oper. Manage. 13 (2004) 23-33.

[17] B.C. Giri and S. Bardhan, Supply chain coordination for a deteriorating item with stock and price-dependent demand under revenue sharing contract. Int. Trans. Oper. Res. 19 (2012) 753-768.

[18] B.C. Giri and S. Bardhan, Coordinating a supply chain with backup supplier through buyback contract under supply disruption and demand uncertainty. Int. J. Syst. Sci. 1 (2014) 193-204.

[19] B.C. Giri and S. Bardhan, Coordinating a supply chain under uncertain demand and random yield in presence of supply disruption. Int. J. Prod. Res. 53 (2015) 5070-5084.

[20] M.G. Güler and M.E. Keski, On coordination under random yield and random demand. Expert Syst. App. 40 (2013) $3688-3695$.

[21] Y. He and J. Zhang, Random yield risk sharing in a two-level supply chain. Int. J. Prod. Econ. 112 (2008) 769-781.

[22] Y. He and X. Zhao, Coordination in multi-echelon supply chain under supply and demand uncertainty. Int. J. Prod. Econ. 139 (2012) 106-115.

[23] B. He, H. Huang and K. Yuan, The comparison of two procurement strategies in the presence of supply disruption. Comput. Ind. Eng. 85 (2015) 296-305.

[24] J. Hou and L. Zhao, Backup agreements with penalty scheme under supply disruption. Int. J. Syst. Sci. 43 (2012) $987-996$.

[25] D. Ivanov, A. Dolgui, B. Sokolov and M. Ivanova, Literature review on disruption recovery in the supply chain. Int. J. Prod. Res. 55 (2017) 6158-6174.

[26] P.R. Kleindorfer and D.J. Wu, Integrating long-and short-term contracting via business-to-business exchanges for capitalintensive industries. Manage. Sci. 49 (2003) 1597-1615.

[27] X. Li, Optimal procurement strategies from suppliers with random yield and all-or-nothing risks. Ann. Oper. Res. 257 (2017) 167-181.

[28] G. Li, L. Li, Y. Zhou and X. Guan, Capacity restoration in a decentralized assembly system with supply disruption risks. Int. Trans. Oper. Res. 24 (2017) 763-782.

[29] R.R. Meyer, M.H. Rothkopf and S.A. Smith, Reliability and inventory in a production-storage system. Manage. Sci. 25 (1979) 799-807.

[30] N. Mohammadzadeh and S.H. Zegordi, Coordination in a triple sourcing supply chain using a cooperative mechanism under disruption. Comput. Ind. Eng. 101 (2016) 194-215.

[31] A.J. Ruiz-Torres and F. Mahmoodi, The optimal number of suppliers considering the costs of individual supplier failures. Omega 35 (2007) 104-115.

[32] M. Savage, Component aftershock hits channel. Comput. Resell. News 1999 (1999) 166.

[33] J.J. Spengler, Vertical integration and antitrust policy. J. Polit. Econ. 58 (1950) 347-352.

[34] C.S. Tang, Perspectives in supply chain risk management. Int. J. Prod. Econ. 103 (2006) 451-488.

[35] B. Tomlin, Disruption-management strategies for short life-cycle products. Nav. Res. Logist. 56 (2009) 318-347.

[36] B. Van Der Rhee, J.A.A. Van Der Veen, V. Venugopal and V.R. Nalla, A new revenue sharing mechanism for coordinating multi-echelon supply chains. Oper. Res. Lett. 38 (2010) 296-301.

[37] X. Xu, Y. Sun and Z. Hua, Reducing the probability of bankruptcy through supply chain coordination. IEEE Trans. Syst. Man Cybern. Part C (App. Rev.) 40 (2010) 201-215.

[38] A.Z. Zeng and Y. Xia, Building a mutually beneficial partnership to ensure backup supply. Omega 52 (2015) 77-91. 